\title{
Halogen Bonds Fabricate 2D Molecular Self-Assembled Nanostructures by Scanning Tunneling Microscopy
}

\author{
Yi Wang, Xinrui Miao * and Wenli Deng * \\ College of Materials Science and Engineering, South China University of Technology, Guangzhou 510640, China; \\ 201810103602@mail.scut.edu.cn \\ * Correspondence: msxrmiao@scut.edu.cn (X.M.); wldeng@scut.edu.cn (W.D.)
}

Received: 30 September 2020; Accepted: 9 November 2020; Published: 20 November 2020

\begin{abstract}
Halogen bonds are currently new noncovalent interactions due to their moderate strength and high directionality, which are widely investigated in crystal engineering. The study about supramolecular two-dimensional architectures on solid surfaces fabricated by halogen bonding has been performed recently. Scanning tunneling microscopy (STM) has the advantages of realizing in situ, real-time, and atomic-level characterization. Our group has carried out molecular self-assembly induced by halogen bonds at the liquid-solid interface for about ten years. In this review, we mainly describe the concept and history of halogen bonding and the progress in the self-assembly of halogen-based organic molecules at the liquid/graphite interface in our laboratory. Our focus is mainly on (1) the effect of position, number, and type of halogen substituent on the formation of nanostructures; (2) the competition and cooperation of the halogen bond and the hydrogen bond; (3) solution concentration and solvent effects on the molecular assembly; and (4) a deep understanding of the self-assembled mechanism by density functional theory (DFT) calculations.
\end{abstract}

Keywords: halogen bonding; $\sigma$-hole interactions; self-assembly; scanning tunneling microscopy

\section{Introduction}

\subsection{The Definition of Halogen Bonds}

A halogen bond $(\mathrm{XB})$ is a broader class of noncovalent interaction, which was defined by the International Union of Pure and Applied Chemistry (IUPAC) in 2013 [1]. This definition states that "A halogen bond occurs when there is evidence of a net attractive interaction between an electrophilic region associated with a halogen atom in a molecular entity and a nucleophilic region in another, or the same, molecular entity." A structural scheme for XB is shown in Figure 1.

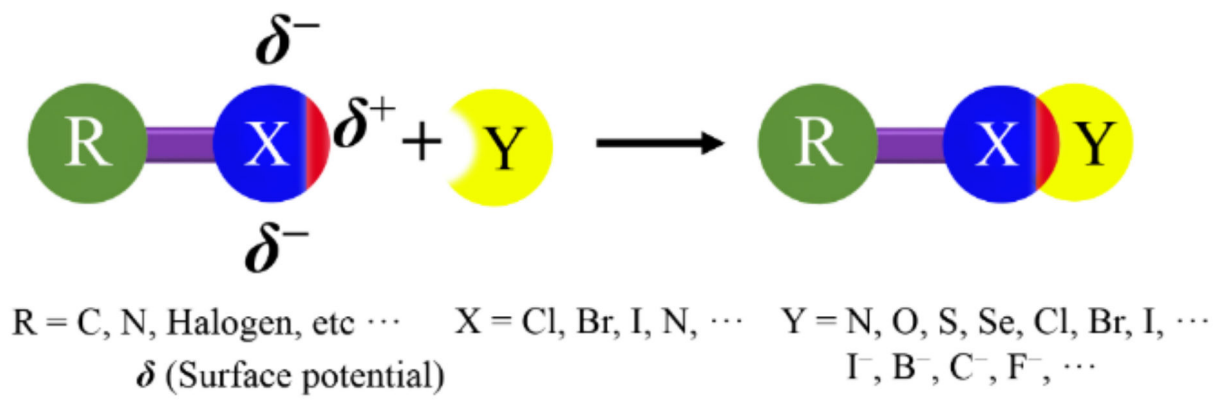

Figure 1. Structural scheme for a halogen bond (XB). 
$\mathrm{XB}$ exhibits a high directionality, because the electron density in halogen atoms is anisotropically distributed [2,3]. In the halogen atoms, a region of lower electron density ( $\sigma$-hole) gives rise to a cap of deficient electron density on the extension of the $\mathrm{R}-\mathrm{X}$ covalent bond, which can act as the attractive electron-rich region. The negative charges form a belt orthogonal to the covalent bond in nearly all cases [4]. In this review, the XBs will be explained by the existence of a positive $\sigma$-hole on top of the halogen atom.

\subsection{The History Perspective of $X B$}

The investigation of the $\mathrm{XB}$ traces back to 200 years ago. The $\mathrm{I}_{2} \cdots \mathrm{NH}_{3}$ halogen-bonded complex was synthesized by Colin in 1814 after iodine was found by chance and separated in 1812 [5]. However, the precise molecular constituent of the iodine/polyiodide complex was ascertained by Guthrie only 50 years later [6]. The complexes involved $\mathrm{Br}$ and $\mathrm{Cl}$ as electron acceptor species and were first reported in the late 19th century by Remsen and Norris [7]. However, the first compound, referred to as $\mathrm{F}_{2}$, was reported nearly 80 years later when the $\mathrm{F}^{3-}$ anion could be isolated under very extreme conditions [8-10]. Moreover, the adducts of $\mathrm{F}_{2} \cdots \mathrm{NH}_{3}$ and $\mathrm{F}_{2} \cdots \mathrm{OH}_{2}$ did not arise until the 1990s [11]. These early-stage experimental data show that the $\mathrm{XB}$ strength is closely related to the polarizability of the $\mathrm{XB}$ donor atom, that is, $\mathrm{F}<\mathrm{Cl}<\mathrm{Br}<\mathrm{I}$. In fact, $\mathrm{F}$ without polarization cannot easily participate in $\mathrm{XB}$ and can serve as an $\mathrm{XB}$ donor only when connecting with exceedingly strong electron-withdrawing groups. A critical interest in the stereo electronic evaluation of the $\mathrm{XB}$ was supported by computational studies on the electron density distribution of halogen atoms in the early 1990s. The studies by T. Brinck, P. Politzer, and J. S. Murray were particularly noteworthy when they revealed the anisotropic charge distribution on halogen atoms forming one covalent bond [12-14], and supported the theoretical basis of the definition of the " $\sigma$-hole": a region of barren and constantly positive electrostatic potential on the surface of halogen atoms. In 2007, a seminal paper by Clark [15] et al. proposed a subtle method of interpreting many properties of $\mathrm{XB}$ via the $\sigma$-hole. A symposium devoted to the $\mathrm{XB}$ was organized by IUPAC in 2009, and some features of the interaction were acknowledged. In 2013, the definition of the XB by IUPAC finally gained the agreement of the scientific community, based on the self-assembly and recognition processes determined by electrophilic halogens. This topic has been well-established, used, and understood up until now.

\subsection{The Investigation and Application of XB Focus on Crystal Engineering}

Over the last seven decades, supramolecular synthesis has attracted great interest from chemists wanting to fabricate new materials based on noncovalent interactions [16-20]. Different self-assembly strategies have been proposed, and new supramolecular systems will be achieved by considering the relevant scientific literature across the years [18,21-23]. To design and synthesize supramolecular self-assembled materials, molecular building blocks with designed functions can be used to self-assemble ordered structures. The self-assembly process can happen in any dimension, which is the comprehensive outcome of the balanced steric effect, shape complementarity, and specific anisotropic interactions in the assembly process. For example, supramolecular synthesis could be involved in fabricating molecular organic frameworks [24,25], molecular acceptors [26], responsive materials [27], organogels [28,29], polymers [30] and biomimetic systems [31-33], as well as in nanoparticle self-assembly $[34,35]$.

In 1968, Bent [36] published an overall review on the crystal structures of XB systems and discussed at length the structural chemistry of donor-acceptor interactions in bulk crystals, in which the $\mathrm{XB}$ and the hydrogen bond $(\mathrm{HB})$ were compared based on their similarities, such as the short interatomic distances and high directionality. Crystal engineering is a self-assembly process in which building blocks can fabricate architectures following the laws of intermolecular interactions and shape complementarity [17,37-40]. Many noncovalent interactions, for example, HB, XB [41], $\pi-\pi$ stacking, metal-ligand coordination, dipole-dipole interactions, and hydrophobic interactions, were used to fabricate molecular crystals. Among these weak interactions, HB is commonly used based on its 
high directionality and moderate strength (25-40 kJ/mol). However, XB similar to HB has not been developed as HB because of the misunderstanding associated with halogen atoms that neutral entities in dihalogens or fully negative elements in halocarbon moieties could not form strong attractive interactions. In general, the strength of $\mathrm{XB}$ is closely related to the magnitudes of the positive and negative areas of the electrostatic potential (ESP). Furthermore, the other chemical factors, such as the electronegativity and polarizability of $X$ atoms [42], the hybridization of the carbon atom bound to the XB donor sites [43], and strong electron-withdrawing moieties [44,45], directly affect the magnitudes of the positive and negative areas so as to tune the strength of the $\mathrm{XB}$ indirectly.

The directionality of $\mathrm{XB}$ refers to the angle between the $\mathrm{R}-\mathrm{X}$ covalent bond and the $\mathrm{X} \cdots \mathrm{X}$ or $\mathrm{Y}$ noncovalent bonds as $\theta_{2}$ shown in type-II XB (Figure 2) [46,47]. The great directionality of such XB is attributed to the bond formation. The nucleophile enters the $\sigma$-hole of the halogen atom, which is narrowly confined on the elongation of the $R-X$ covalent bond axis. The $R-X \cdots Y$ angle between the covalent and noncovalent bonds around the halogen is approximately $180^{\circ}$ [46,47]. Although HB is another simple type of $\sigma$-hole interaction, the positive regions on linked hydrogens tend to be almost hemispherical due to hydrogen having only one electron [48-50]. Therefore, the XB is a particularly directional interaction compared to the HB. In 1963, the R-X $\cdots$ X-R bond with different contact geometries was proposed by Sakurai [44] et al., which was classified as type-I and type-II, as illustrated in Figure 2 [51]. There is a clear geometric and chemical distinction between type-I and type-II X...X interactions. The type-I interaction is not XB according to the IUPAC definition. It is a geometry-based contact arising from the close-packing requirement, which is observed for all halogens. The type-II interaction arises from the pairing between the electrophilic area on one halogen atom and the nucleophilic area on the other [52]. Moreover, many investigations reveal that the type-II interaction is most favored by the order of iodinated derivatives $>$ brominated derivatives $>$ chlorinated derivatives.

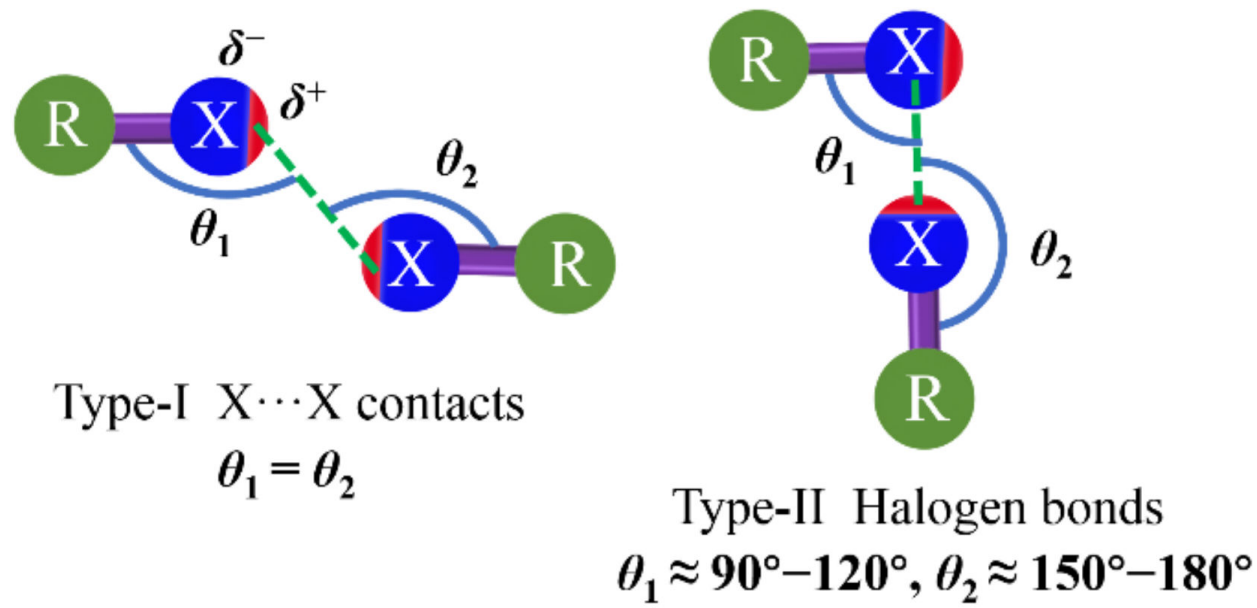

Figure 2. Structural scheme for type-I (left) and type-II (right) halogen $\cdots$ halogen interactions. $X=$ halogen atom; $\mathrm{R}=\mathrm{C}, \mathrm{N}, \mathrm{O}$, halogen atom, etc.; $\delta$ is surface potential. Type-II interaction is $\mathrm{XB}$.

In addition, halogen atoms are typically regarded as hydrophobic residues. For example, an I or $\mathrm{Br}$ atom is less hydrophilic than a typical $\mathrm{HB}$ donor such as an $\mathrm{OH}$ or $\mathrm{NH}$ group. From the nature of the discrepancy between the two donor sites arise many useful and complementary applications. 


\subsection{The General Description of XB in $2 D$ Crystal Engineering}

Similar to 3D self-assembly processes, the molecular self-assembly process on surfaces can be controlled by balancing molecule-molecule and molecule-substrate interactions $[46,47,51-53]$. The intermolecular non-covalent bond of XB with high directionality, moderate bond strength (5-30 kJ/mol), and its binding geometry has been used to fabricate 2D nanostructures [40,54-59]. Because of the large size of the halogen atom and the existence of the $\sigma$-hole, $\mathrm{XB}$ is more sensitive to the steric hindrance and directionality than $\mathrm{HB}[4,60]$. However, as a powerful tool to tune the 2D nanoarchitectures on surfaces, halogens are usually involved in forming $\mathrm{HB}$ (total interaction energies up to $140 \mathrm{~kJ} / \mathrm{mol}$ ), where they sever as Lewis bases, and the strength of HBs involving halogens varies with $\mathrm{F}>\mathrm{Cl}>\mathrm{Br}>\mathrm{I}$ [61]. Perhaps they can form XBs serving as Lewis acids with an opposite trend, meaning that the strength of the interaction can be tuned by varying halogen substituents. This trend depends on the strength of the $\sigma$-hole, which in turn relates to the electron-withdrawing ability of the group. Significantly, XBs are independent from HBs, so both types of interactions can be used to design and adjust supramolecular 2D assemblies on the surface at the same time.

Scanning tunneling microscopy (STM) is a powerful tool that can be used to probe the surface locally and provide structural information in a submolecular resolution whether the nanostructure is crystalline or amorphous [62,63]. The instrument can be used in diverse types of environments such as ultra-high vacuum (UHV), air, and liquid. The temperature of the surface can be precisely controlled (ranging from $\sim 4 \mathrm{~K}$ up to a few hundred Kelvin) in a vacuum, which permits both controlled annealing and imaging at low temperatures. UHV provides an ultra-clean environment, which is essential for quantifying supramolecular interactions that are relatively hard to be understood in the solution phase. The solution phase offers a "real-life" view of the assembly process involved in the competition of molecule-solvent and solvent-substrate interactions, except for the molecule-molecule and molecule-substrate interactions [64].

This review will concentrate on our recent research work about 2D supramolecular assembled systems associated with XBs in ambient conditions. Through this review, a comprehensive discussion of supramolecular self-assembled adlayers stabilized by various XBs will be provided. Though it is much more likely to be accepted that the $\mathrm{HB}$ is a relatively stronger intermolecular interaction than the $\mathrm{XB}$. In some cases, the $\mathrm{XB}$ can be of equivalent strength or even stronger than the typical HB. XB has been widely used to direct and control assembly processes depending on the molecular recognition [40,65-70]. However, the studies of XBs in 2D surface crystal engineering only date back to the last 15 years. Therefore, this is a hot topic in an ongoing research field, and there are many unknown mechanisms that need to be explored.

\section{Halogen-Halogen Interactions and Halogen-Bonding in 2D Self-Assembled Networks}

To confirm that supramolecular networks are exactly controlled by XBs, a rational design of the building block is essential. Theories of XBs have already been established in 3D crystal engineering, which can be easily applied on 2D assembly, even though differences exist because of the substrate effect. In the following sections, we focus on the research work in our laboratory and discuss the self-assembled patterns fabricated by different halogenated building blocks listed in Scheme 1. The discussion is mainly classified based on the species of $\pi$-conjugated cores. 


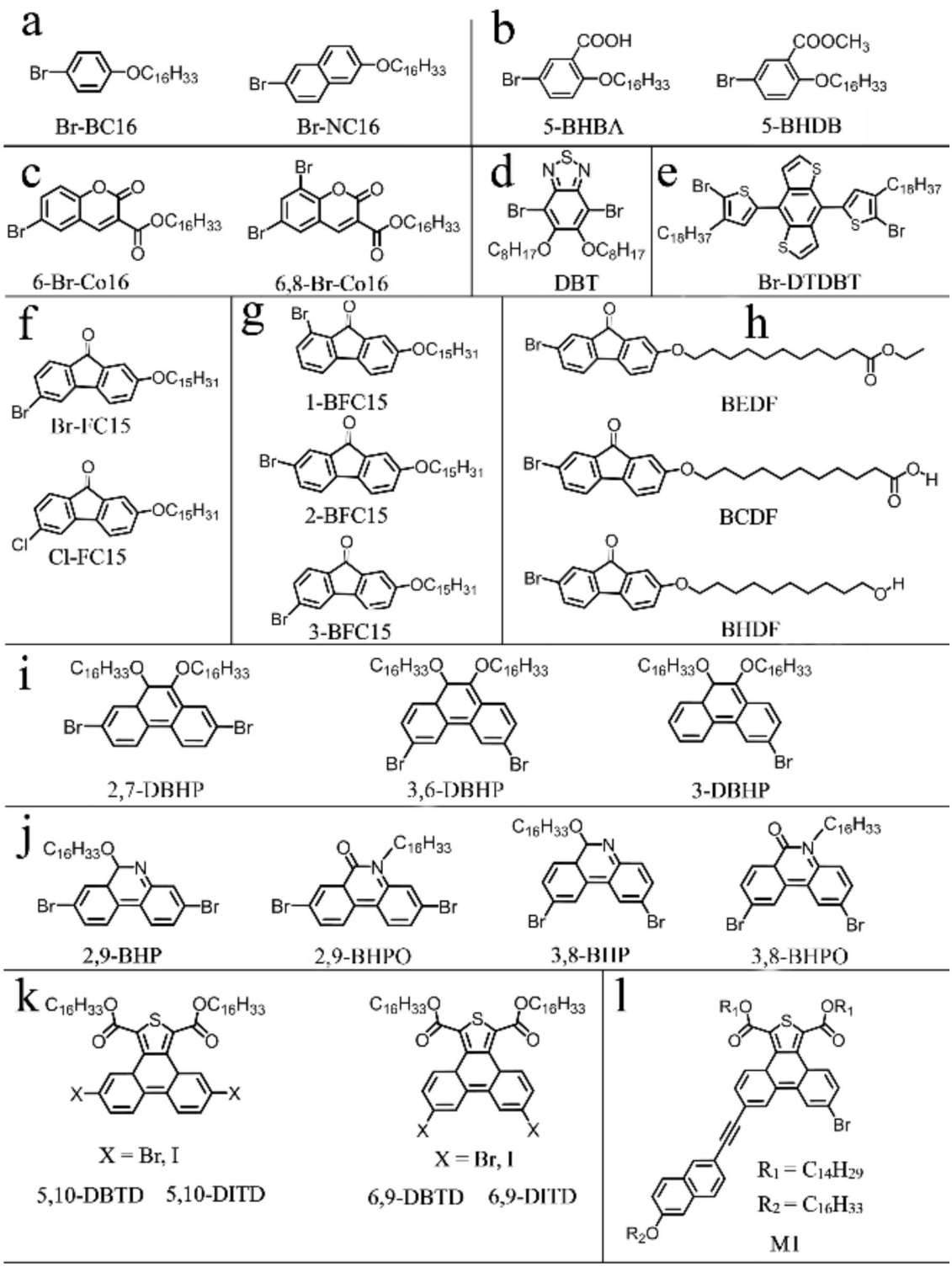

Scheme 1. Chemical structures of the halogenated molecules. (a) Molecules with different geometry symmetries of $\pi$-conjugated cores along $\mathrm{C}-\mathrm{Br}$ bond (Br-BC16 and $\mathrm{Br}-\mathrm{NC} 16)$. (b) Bifunctional benzene derivatives (5-BHBA and 5-BHDB). (c) Bromine substituted coumarin derivatives (6-Br-Co16 and 6,8-Br-Co16). (d) Thiadiazole derivative (DBT). (e) Dithiophene derivative (Br-BTDBT). (f) Different halogen substituted (Br, Cl, and F) fluorenone derivatives (Br-FC15, Cl-FC15, and F-FC15). (g) Fluorenone derivatives with different positions of Br substituents (1-BFC15, 2-BFC15, and 3-BFC15). (h) Fluorenone derivatives with different terminal groups (BEDF, BCDF, and BHDF). (i) Phenanthrene derivatives with different numbers and positions of halogen substituents on the $\pi$-conjugated cores (2,7-DBHP, 3,6-DBHP, and 3-DBHP). (j) Four regioisomeric phenanthridine derivatives with different positions of halogen substituents and alkoxy chains (2,9-BHP, 2,9-BHPO, 3,8-BHP, and 3,8-BHPO). (k) Thienophenanthrene derivatives with different positions of halogen substituents on the $\pi$-conjugated cores (6,9-DBTD and 5,10-DBTD). (1) An asymmetric thienophenanthrene derivative (M1). All the 28 molecules are used to investigate the 2D supramolecular self-assembled nanostructures based on XBs in our group. 


\subsection{The Effect of Geometry Symmetry of $\pi$-Conjugated Cores Along the $\mathrm{C}-\mathrm{Br}$ Bond}

Varying the geometry of $\pi$-conjugated cores can influence the outcome of the self-assembly nanostructures. This aspect can be indicated by the bromine-substituted benzene derivative (Br-BC16) and naphthalene derivative (Br-NC16) (Scheme 1a) [71]. Self-assembled patterns of Br-BC16 and Br-NC16 compounds were studied by STM at the 1-octanoic acid/graphite interface, comparatively (Figure 3). STM results show that the two molecules form different linear fashions stabilized by

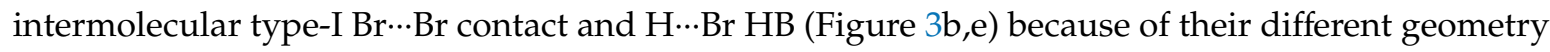
symmetries of $\pi$-conjugated cores along the $\mathrm{C}-\mathrm{Br}$ covalent bond. The $\pi$-conjugated cores and side chains of Br-BC16 absorb with the same direction, while the side chains of Br-NC16 extend into different directions along the lattices of graphite substrate. The $\pi$-conjugated cores of two kinds of molecules form a dimer and arrange in a head-to-head mode by a pair of $\mathrm{H} \cdots \mathrm{Br} \mathrm{HB}$ with an antiparallel style.
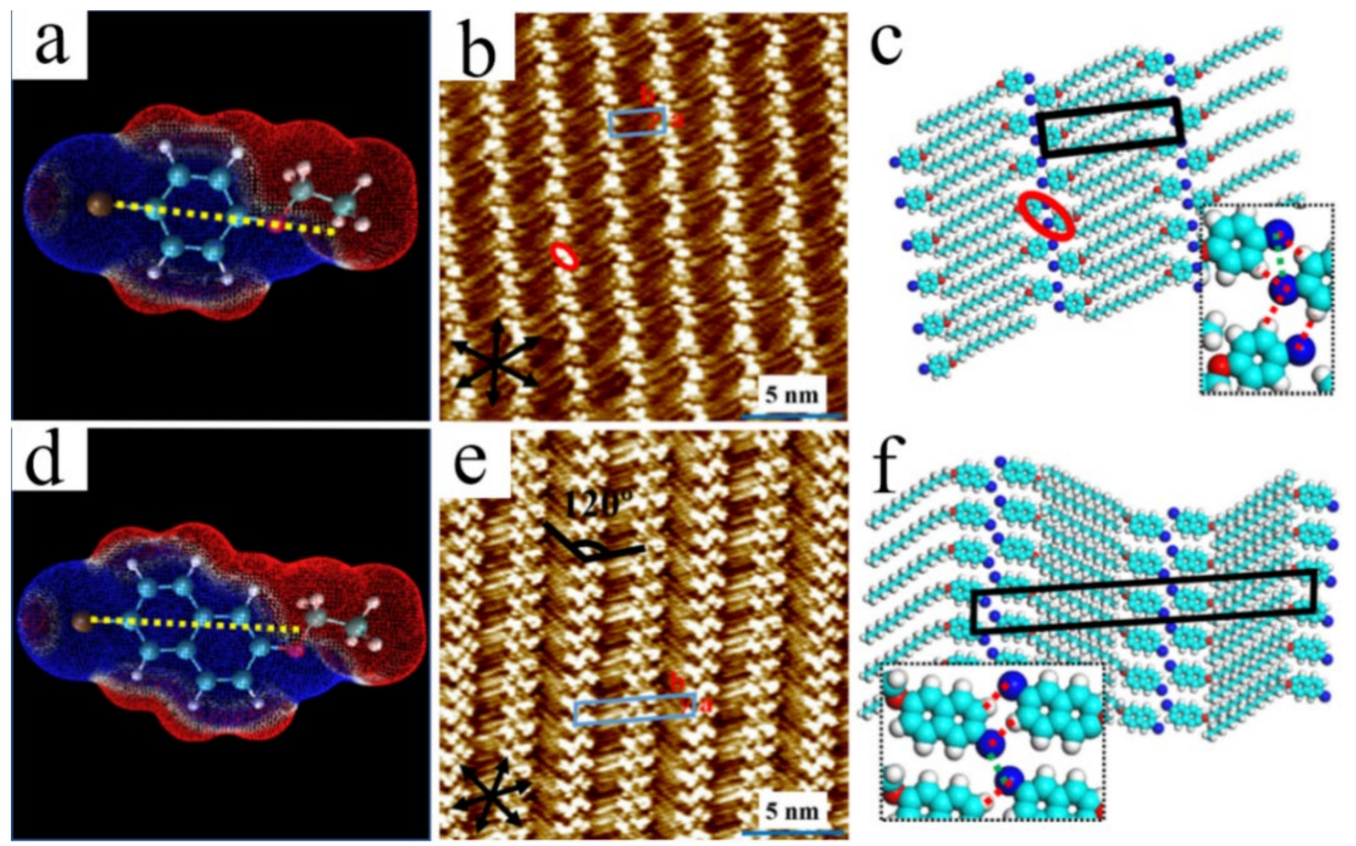

Figure 3. (a,d) Calculated electrostatic potential (ESP) maps of Br-BC16 and Br-NC16 under vacuum shown by red (positive) and blue (negative) regions. (b,e) High-resolution STM images of adlayers formed by Br-BC16 and Br-NC16 at the 1-octanoic acid/graphite interface. (c,f) Proposed molecular models for $(\mathbf{b}, \mathbf{e})$. Insets show the intermolecular interactions. The red lines show the $\mathrm{H} \cdots \mathrm{Br}$ bonds, and the green lines show the $\mathrm{Br} \cdots \mathrm{Br}$ contact. Reproduced from [71] with permission from the American Chemical Society.

Calculated 3D ESP maps of $\pi$-conjugated cores (Br-BC16 and Br-NC16, Figure 3a,d) and quantum theory of atoms in molecules (QTAIM) of Bader [72,73] obtained by DFT calculations were used to reveal the formation of intermolecular type-I $\mathrm{Br} \cdots \mathrm{Br}$ contact and $\mathrm{HB}$. The results show that a pair of intermolecular $\mathrm{H} \cdots \mathrm{Br} \mathrm{HBs}$ in each dimer control the structural formation. Furthermore, the type-I $\mathrm{Br} \cdots \mathrm{Br}$ contact is formed in the dimer of $\mathrm{Br}-\mathrm{BC} 16$ and the neighboring dimer of $\mathrm{Br}-\mathrm{NC} 16$, respectively, which is the dominant force to stabilize the two linear nanostructures (Figure 3c,f). It is concluded that the geometry symmetry of $\pi$-conjugated cores along the $\mathrm{C}-\mathrm{Br}$ bond influences the $2 \mathrm{D}$ self-assembly. At the same time, the results also indicate that the type- $\mathrm{I} \mathrm{Br \cdots Br}$ contact is often accompanied by the HB supported by the same $\mathrm{Br}$ atom [40]. 


\subsection{Bifunctional Effect of Benzene Derivative}

We synthesized a bifunctional molecule (5-BHBA, Scheme $1 \mathrm{~b}$ ), and its $2 \mathrm{D}$ self-assembled nanostructures were investigated using STM and DFT calculations [74]. STM experiments were carried out at the 1-octanoic acid/highly oriented pyrolytic graphite (HOPG) interface by varying solution concentrations. Four kinds of patterns (T-like, dislocated, lip-like, and alternating patterns) were observed, as shown in Figure 4a-d. Because of the cooperative and competitive intermolecular $\mathrm{XB}$ and $\mathrm{HB}$, these nanostructures consist of dimers, trimers, and tetramers based on rectangular $-\mathrm{COOH} \cdots \mathrm{HOOC}-\mathrm{HB}$, triangular $\mathrm{COO} \cdots \mathrm{Br} \cdots \mathrm{H}-\mathrm{C}, \mathrm{Br} \cdots \mathrm{O}(\mathrm{H}), \mathrm{Br} \cdots \mathrm{Br}$, and $\mathrm{O} \cdots \mathrm{H}$ interactions. At saturated concentration, the T-like pattern is formed (Figure 4a) comprising of two kinds of dimers (the planes of the horizontal and oblique dimer). Every two molecules form a dimer with a head-to-head style. Figure $4 \mathrm{e}$ shows that double $-\mathrm{Br} \cdots \mathrm{OOC}-\mathrm{XBs}$ and $\mathrm{Br} \cdots \mathrm{H}$ HBs are formed in the horizontal dimers, as indicated by the black and blue dashed lines, respectively. In the oblique dimers, two carboxyl groups form - $\mathrm{COOH}$-.HOOC- HBs. When decreasing the concentration of 5-BHBA, the molecules self-assemble into a dislocated structure (Figure 4b). There are two different parts (domain 1 and 2). The domain 1 is formed by dimers and trimers alternately, while the domain 2 is composed of pure tetramers. The dimers are still stabilized by intermolecular double $-\mathrm{COO} \cdots \mathrm{Br}-\mathrm{XBs}$. However, in each trimer, molecules are connected by the type-I $\mathrm{Br} \cdots \mathrm{Br}$ contact and-COOH $\cdots \mathrm{HOOC}-\mathrm{HBs}$ (Figure 4f). In each tetramer of domain 2, the arrangement is stabilized by the type- $\mathrm{I} \mathrm{Br} \cdots \mathrm{Br}$ contact and $\mathrm{HBs}$. The type-I $\mathrm{Br} \cdots \mathrm{Br}$ interaction is formed resulting from the close packing, and thus its binding energy is weaker than that of the type-II XB [75].

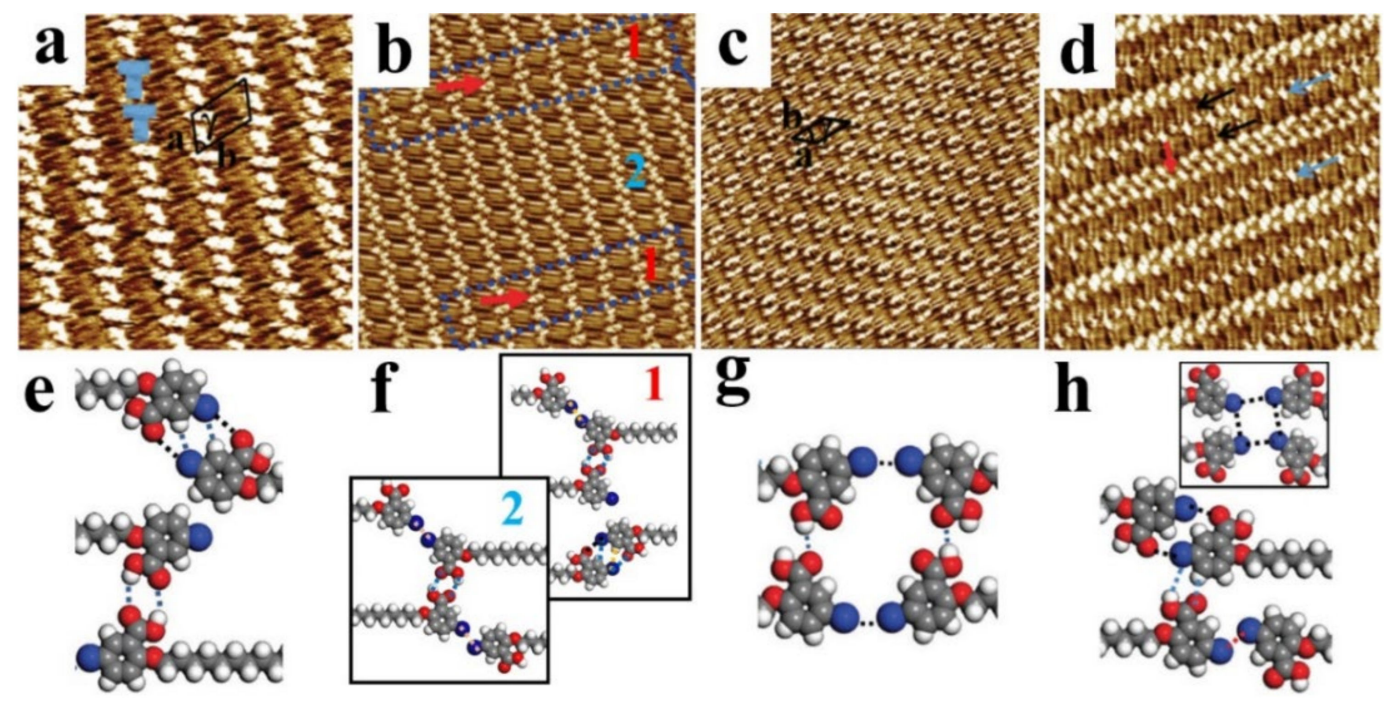

Figure 4. (a-d) High-resolution STM images show the self-assembled T-like, dislocated, lip-like, and alternate patterns for the 5-BHBA adlayers at the 1-octanoic acid/highly oriented pyrolytic graphite (HOPG) interface by continually diluting concentration. Scanning areas: (a) $20 \times 20 \mathrm{~nm}^{2}$; (b) $30 \times 30 \mathrm{~nm}^{2}$; (c) $35 \times 35 \mathrm{~nm}^{2}$; (d) $42 \times 42 \mathrm{~nm}^{2}$. (e-h) Proposed molecular models for the assembly patterns of (a-d). Reproduced from [74] with permission from the Royal Society of Chemistry.

When further diluting the solution, the ordered lip-like structure is observed (Figure 4c). The tetramer is found, which is connected by double type-I $\mathrm{Br} \cdots \mathrm{Br}$ contacts and $-\mathrm{OH} \cdots \mathrm{OOC}-\mathrm{HBs}$ (Figure 4g). Obviously, the type-I $\mathrm{Br} \cdots \mathrm{Br}$ interaction is weaker in binding energy than the $-\mathrm{Br} \cdots \mathrm{OOC}-$ $\mathrm{XB}$ and the $-\mathrm{COOH} \cdots \mathrm{HOOC}-\mathrm{HB}$. However, only one HB exists between the carboxyl groups rather than the conventional strong rectangle HBs, which indicates that the lip-like pattern is a metastable phase. At low concentrations, a well-ordered 2D alternated nanoarchitecture is observed (Figure 4d). In one-row lamellae, molecules connect with co-adsorbed 1-octanoic acid molecules by - $\mathrm{Br}$ ‥OOCXBs [76]. However, in two-row lamellae, the tetramers are formed, which are stabilized by the weak 


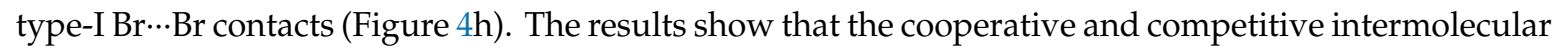
$\mathrm{HBs}, \mathrm{XBs}$, and $\mathrm{Br} \cdots \mathrm{Br}$ interactions could induce the structural diversity under different concentrations.

Another similar molecule (5-BHDB) mixed with 1-BH (Scheme 1b and Figure 5a) was investigated by dropping the solution on the HOPG surface [77]. The mixture can form a host-guest self-assembled structure. Polar solvent (1-octanoic acid) and nonpolar solvents (1-phenyloctane, $n$-pentadecane, $n$-tetradecane, and $n$-decane) are used to explore the solvent effect. ESP maps (Figure $5 \mathrm{~b}$ ) show the charge distribution of the $\pi$-conjugated core. In 1-octanoic acid, the host-guest linear I nanostructure consisting of trimers is observed, which is stabilized by the intermolecular XBs (Figure 5c). This nanostructure is also observed in other solvents at high solution concentrations. When further decreasing the solution concentration, another double-line host-guest nanostructure (linear II, Figure 5d) containing trimers and tetramers is formed in 1-phenyloctane. Co-adsorbed solvent molecules could occupy the gap between side chains in the linear II pattern. Moreover, in $n$-pentadecane and $n$-tetradecane, the wavelike structures (Figure 5e) were also observed based on the solvent co-adsorption behavior. Therefore, the van der Waals (vdW) forces of molecule-solvent and the intermolecular XB dominate the formation of co-adsorbed patterns. In $n$-decane, the linear III pattern (Figure $5 \mathrm{f}$ ) is observed, driven by the $\mathrm{Br} \cdots \mathrm{Br}$ type-I contact and the Br. Br type-II XB. In combination with DFT calculations, it is concluded that XBs induce the formation of each structure, and the emergence of relatively stronger host-guest XBs plays a key role in stabilizing these nanostructures and inducing the structural transition.

a

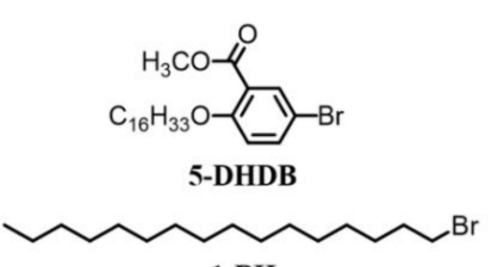

1-BH

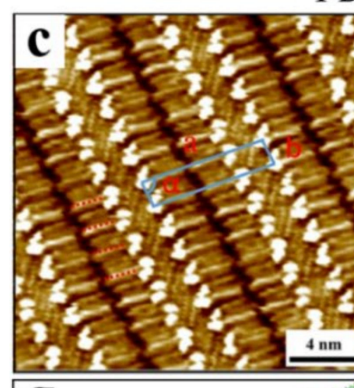

\section{g}

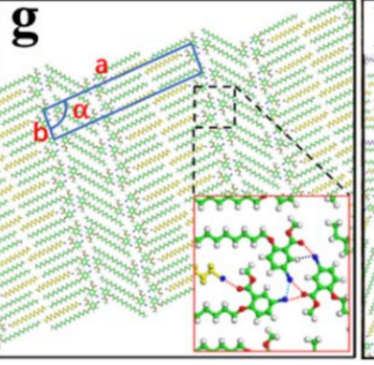

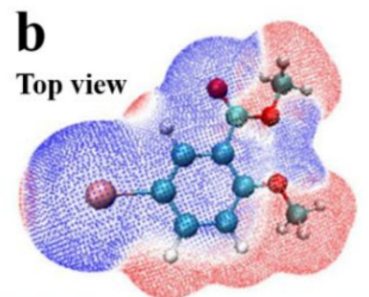
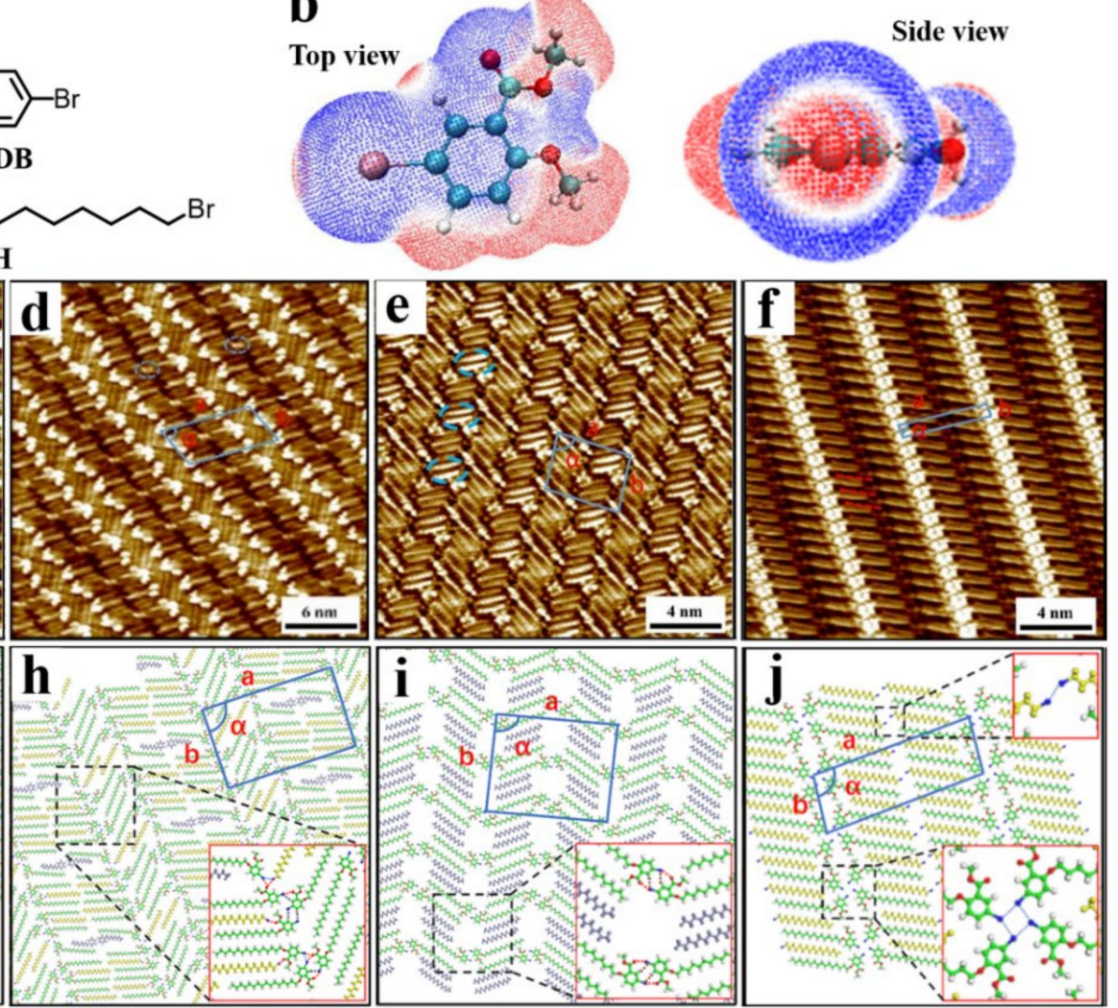

Figure 5. (a) Chemical structures of 5-BHDB and 1-BH. (b) Top and side views of the calculated 3D ESP map of 5-BHDB molecule. (c-f) High-resolution STM images showing the self-assembled linear I, linear II, wavelike, and linear III patterns for the 5-BHBA adlayers in 1-octanoic acid, 1-phenyloctane, $n$-pentadecane, and $n$-decane, respectively. $(\mathbf{g}-\mathbf{j})$ Proposed molecular models for the assembly (c-f) of the 5-BHBA. Reproduced from [77] with permission from the American Chemical Society. 


\subsection{Self-Assembled Patterns of Coumarin Derivatives at the 1-Phenyloctane/HOPG Interface}

Two coumarin derivatives substituted by one bromine and two bromines (6-Br-Co16 and $6,8-\mathrm{Br}-\mathrm{Co} 16)$ were synthesized and shown in Figure $6 \mathrm{a}$,d and Scheme 1c [78]. STM results show that 6-Br-Co16 molecules self-assemble into a uniform Z-like linear pattern (Figure 6b). Two 6-Br-Co16 molecules form a dimer adopting an antiparallel orientation through a pair of triangular motifs

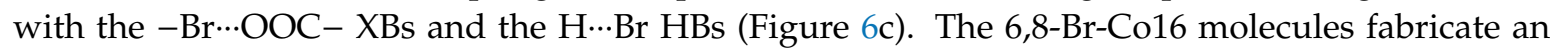
ordered dislocated linear pattern. In each lamella, the adjacent coumarin cores form a dimer by the same bonding motif as 6-Br-Co16, whereas unlike 6-Br-Co16, the adjacent dimers of 6,8-Br-Co16 align in a tail-to-tail style with type-II $\mathrm{Br} \cdots \mathrm{Br} \mathrm{XB}$ and $\mathrm{H} \cdots \mathrm{Br} \mathrm{HB}$, leading to their structural difference. The dominant factors in the 2D self-assembled adlayers of the two coumarin derivatives refer to the position and number of $\mathrm{Br}$ substituents. Because $\mathrm{Br}$ atoms are electron withdrawing groups (strong electronegativity) and highly polarizable, they can induce the rearrangement of the electronic density distribution of the molecules. It is concluded that the $\mathrm{Br}$ atom can participant in the formation of the $-\mathrm{Br} \cdots \mathrm{OOC}-\mathrm{XB}$ to induce the formation of different $2 \mathrm{D}$ adlayers.

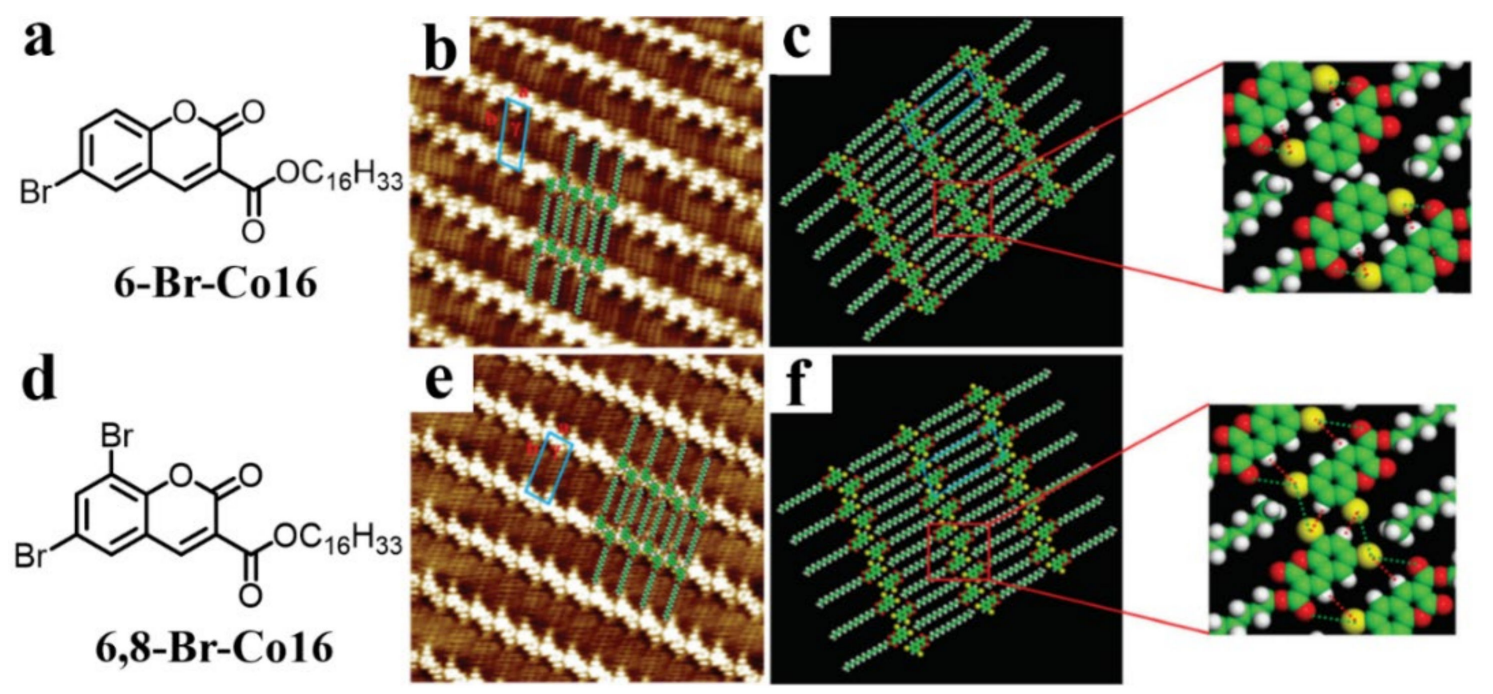

Figure 6. (a,d) Molecular structures of 6-Br-Co16 and 6,8-Br-Co16. (b,e) High-resolution STM images of the 6-Br-Co16 and 6,8-Br-Co16 physiosorbed monolayers at the 1-phenyloctane/HOPG interface. Scanning area: $20 \times 20 \mathrm{~nm}^{2}$. (c,f) Proposed molecular models of $(\mathbf{b}, \mathbf{e})$. The inset shows the possible intermolecular bonds. Reproduced from [78] with permission from the Royal Society of Chemistry.

\subsection{Self-Assembled Patterns of Thiadiazole Derivatives at the Liquid/HOPG Interface}

Self-assembled nanoarchitectures of the DBT molecule (Scheme 1d) were investigated by STM at the liquid/HOPG interface in three kinds of solvents (1-phenyloctane, 1-octanoic acid, and 1-octanol) [79]. Dramatic differences in 2D self-assembly patterns are observed. In 1-phenyloctane, a linear structure (Figure 7a) is stabilized by type-I $\mathrm{Br} \cdots \mathrm{Br}$ contacts (Figure $7 \mathrm{~b}$ ). However, a lamellar structure is formed at the 1-octanoic acid or 1-octanol/HOPG interface (Figure 7c,e), in which the solvent molecules serve as co-adsorbed components to form the HBs with DBT molecules. The distinct self-assembled nanostructures could be attributed to the solvent polarity. Therefore, the solvent effect plays a significant role in tuning self-assembled nanostructures on solid surfaces. 


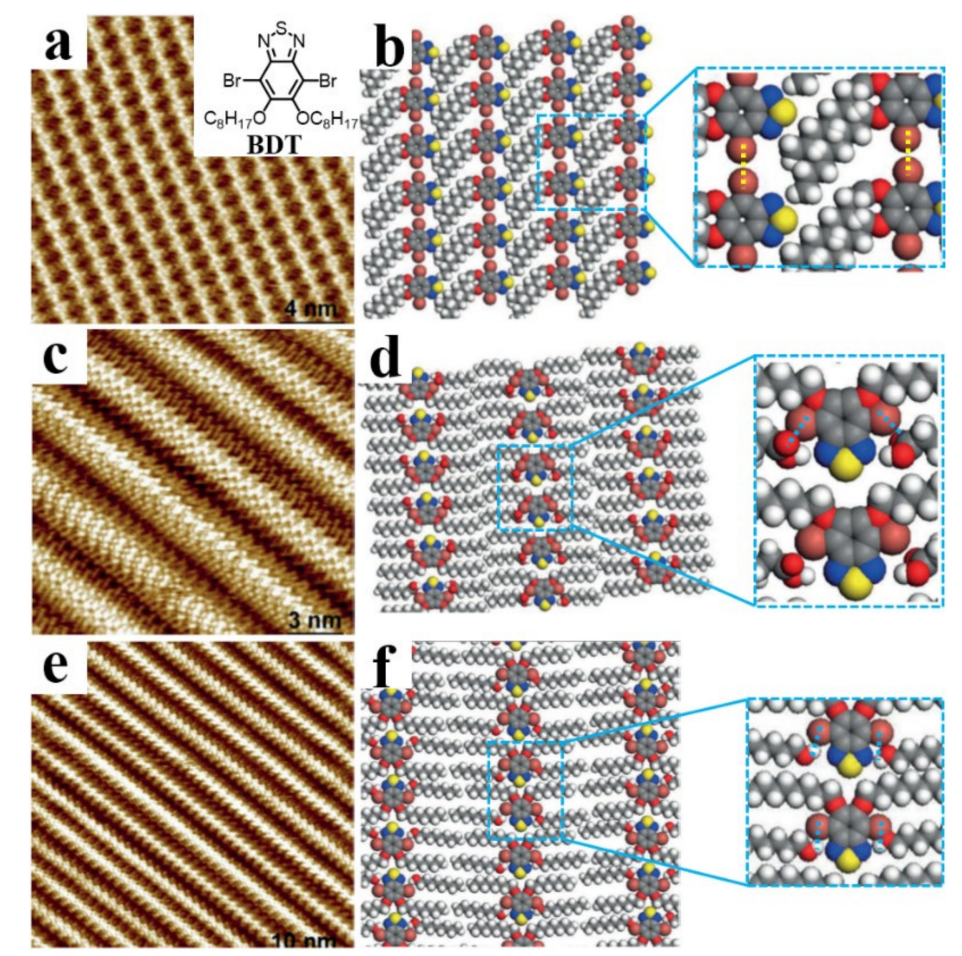

Figure 7. (a,c,e) High resolution STM images of DBT adlayers in 1-phenyloctane, 1-octanoic acid, and 1-octanol, respectively. (b,d,f) proposed structure models of $(\mathbf{a}, \mathbf{c}, \mathbf{e})$ for the DBT adlayers. Possible interactions are shown in the enlarged insets by yellow and blue dashed lines. Reproduced from [79] with permission from the Hindawi.

\subsection{Self-Assembled Patterns of Dithiophene Derivative at the Liquid/HOPG Interface}

The self-assembly of Br-DTBDT molecule (Scheme 1e) with a cross structure on HOPG surface was studied by STM and DFT calculations (Figure 8a,b) [80]. The self-assembled pattern is shown in the high-resolution STM image (Figure 8c). The proposed model (Figure 8d) implies that the intermolecular Br..S XBs are formed in neighboring molecules, which are the dominant forces to stabilize the well-ordered 2D self-assembled pattern. The bonding mode is also indicated by the ESP map (Figure $8 b$ ), in which the charge distribution of $\mathrm{Br}$ atom with an electropositive $\sigma$-hole and the electronegative area of sulfur atoms provide the possibility to form $\mathrm{Br} \cdots \mathrm{S}$ XBs.

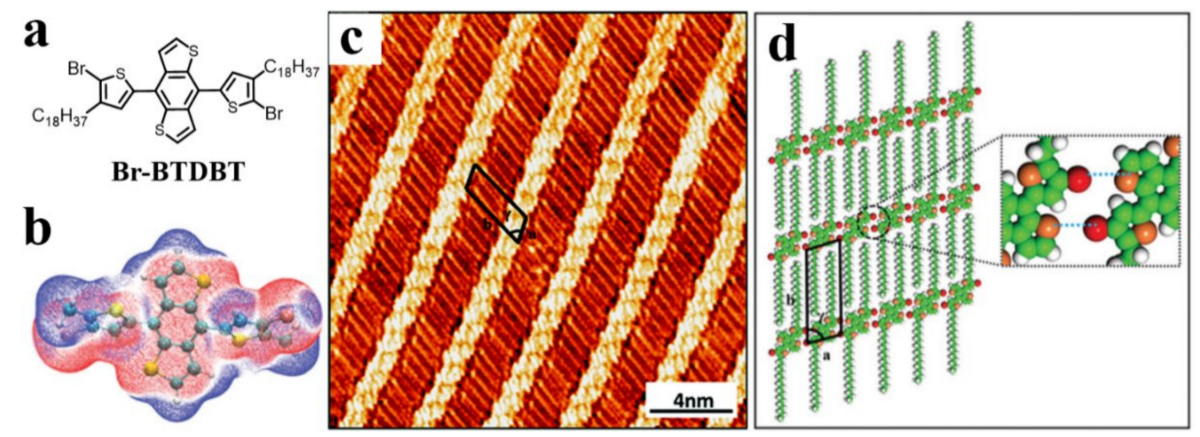

Figure 8. (a) Chemical structure of Br-BTDBT. (b) Calculated 3D ESP map of Br-BTDBT core, note that the alkyl side chains are replaced by the methyl groups for brevity. (c) High-resolution STM image of the adlayer formed by Br-DTBDT at the 1-phenyloctane/HOPG interface. (d) Proposed molecular model of the linear structure. Inset shows the intermolecular interactions. Reproduced from [80] with permission from the Royal Society of Chemistry. 


\subsection{Self-Assembled Patterns of Fluorenone Derivatives at the Liquid/HOPG Interface}

Varying the solution concentrations and the halogen substituents are quite significant to adjust the 2D self-assembled pattern. The mechanism is illustrated by comparing self-assembly of Br-FC15 and Cl-FC15 (Scheme 1f and Figure 9a,b) under different concentrations at the 1-phenyloctane/HOPG interface [81]. At high solution concentrations, a lamellar pattern of Br-FC15 is observed (Figure 9c). The molecules in adjoining sides align in antiparallel via $\mathrm{C}-\mathrm{H} \cdots \mathrm{Br}$ HBs and type-I Br..Br contacts (Figure 9d), which is also formed by Cl-FC15 at high solution concentrations (Figure 9e). However, at low solution concentrations of $\mathrm{Cl}-\mathrm{FC} 15$, twelve $\mathrm{Cl}-\mathrm{FC} 15$ molecules arrange with two-row and form a dodecamer (Figure 9f). The basic unit of the dumbbell-like pattern is formed by a dodecamer with a neighboring one-row tetramer in each trough, which is stabilized by $\mathrm{C}-\mathrm{H} \cdots \mathrm{Cl}$ and $\mathrm{C}-\mathrm{H} \cdots \mathrm{O}-\mathrm{C} \mathrm{HBs}$ (Figure 9j). DFT calculations clearly indicate that the binding energies for the $\mathrm{Br} \cdots \mathrm{Br}(-0.19 \mathrm{kcal} / \mathrm{mol})$ and $\mathrm{Cl} \cdots \mathrm{Cl}(-0.19 \mathrm{kcal} / \mathrm{mol})$ are equivalent, so the similar patterns on surface are formed. Therefore, the differences in molecular packing plausibly might arise from the different charge distribution according to ESP maps (Figure $9 \mathrm{~b}$ ) between the $\mathrm{Br}$ and $\mathrm{Cl}$ atoms, and the nanoarchitectures can be effectively tailored by the introduction of different halogen atoms.

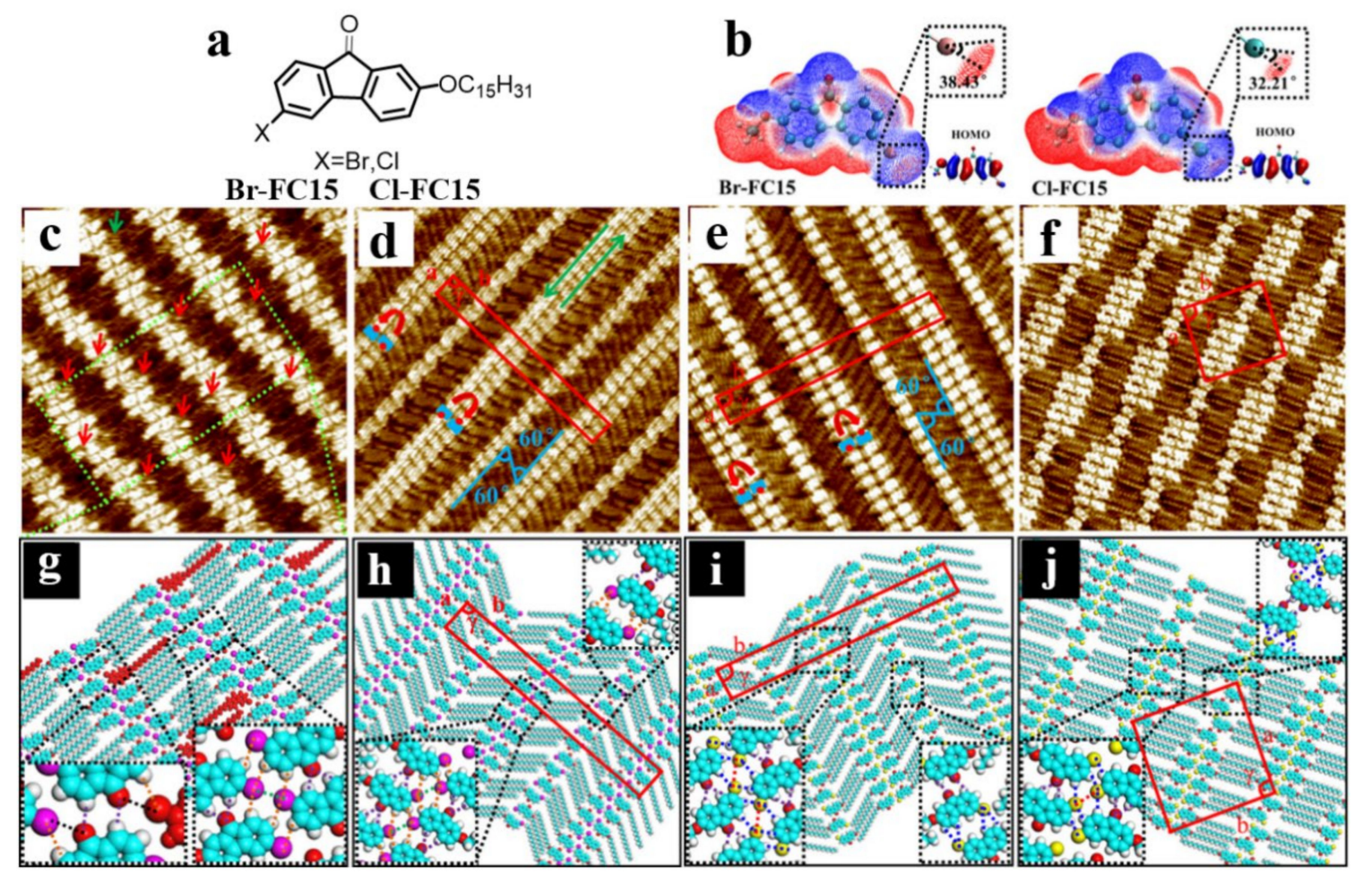

Figure 9. (a,b) Chemical structures of Br-FC15 and $\mathrm{Cl}-\mathrm{ClC} 15$, and their calculated 3D ESP maps. (c-f) High-resolution STM images of the self-assembled lamellar and alternate-I patterns (Br-FC15), as well as alternate-II and dumbbell-like patterns (Cl-FC15) at the 1-phenyloctane/HOPG interface. Concentration: (c) $3.5 \times 10^{-4} \mathrm{M}$; (d) $5.4 \times 10^{-5} \mathrm{M}$; (e) $4.5 \times 10^{-4} \mathrm{M}$; (f) $6.1 \times 10^{-5} \mathrm{M}$. (g-j) Tentative structural models of $(\mathbf{c}-\mathbf{f})$. Intermolecular interactions are reflected in the enlarged insets. Reproduced from [81] with permission from the American Chemical Society.

Varying the position of Br substituents on the $\pi$-conjugated core also affects the self-assembled pattern. This mechanism can be explained by combining STM experiments and DFT calculations. The self-assembly of fluorenone derivatives (1-BFC15, 2-BFC15, and 3-BFC15) with different positions of Br substitution at the 1-octanoic acid/HOPG interface were investigated (Scheme 1g) [82]. The ESP maps of those molecules are shown in Figure 10a-c. Four self-assembled nanostructures: alternate-I pattern (Figure 10d, 1-BFC15), alternate-II pattern (Figure 10e, 2-BFC15), lamellar (Figure 10f, 3-BFC15), 
and alternate-III patterns (Figure 10g, 3-BFC15) are observed. The alternate-I pattern is stabilized by $\mathrm{C}-\mathrm{Br} \cdots \mathrm{O}=\mathrm{C} \mathrm{XB}$ and type-I $\mathrm{Br} \cdots \mathrm{Br}$ contact in the one-row troughs (Figure 10h). In the tetramers of the denser two-row troughs, two diagonal molecules align in an antiparallel fashion bonded with a pair of $\mathrm{C}-\mathrm{H} \cdots \mathrm{Br}$ HBs and connect with the neighboring molecules on the same side through two $\mathrm{C}-\mathrm{H} \cdots \mathrm{Br}$ HBs (Figure 10h). Besides, $\mathrm{C}-\mathrm{H} \cdots \mathrm{O}=\mathrm{C}$ HBs are formed between the tetramers. In the looser two-row troughs, there is lack of $\mathrm{C}-\mathrm{H} \cdots \mathrm{Br} \mathrm{HB}$ between the diagonal molecules compared with the denser two-row troughs. The carboxyl group of 1-octanoic acid molecules interacts with the Br group to form the $\mathrm{COOH} \cdots \mathrm{Br} \mathrm{HB}$ and $\mathrm{C}-\mathrm{Br} \cdots \mathrm{O}=\mathrm{C}(\mathrm{COOH}) \mathrm{XB}$ (Figure 10h). The 2-BFC15 molecules form the alternate-II pattern (Figure 10e). In the one-row troughs, 2-BFC15 molecules point to the same direction of the trough and align along the trough with a small angle between molecules. Tetramers serve as the elementary unit of the two-row troughs and sequentially align along the troughs (Figure 10i), which contains two dimers bonded by the Br $\cdots$ Br type-I contacts, $\mathrm{C}-\mathrm{Br} \cdots \mathrm{O}=\mathrm{C}$ XBs, and $\mathrm{C}-\mathrm{H} \cdots \mathrm{Br} \mathrm{HBs}$. Besides, $\mathrm{C}-\mathrm{H} \cdots \mathrm{O}=\mathrm{C}$ and $\mathrm{C}-\mathrm{H} \cdots \mathrm{Br}$ HBs are formed between the two dimers.

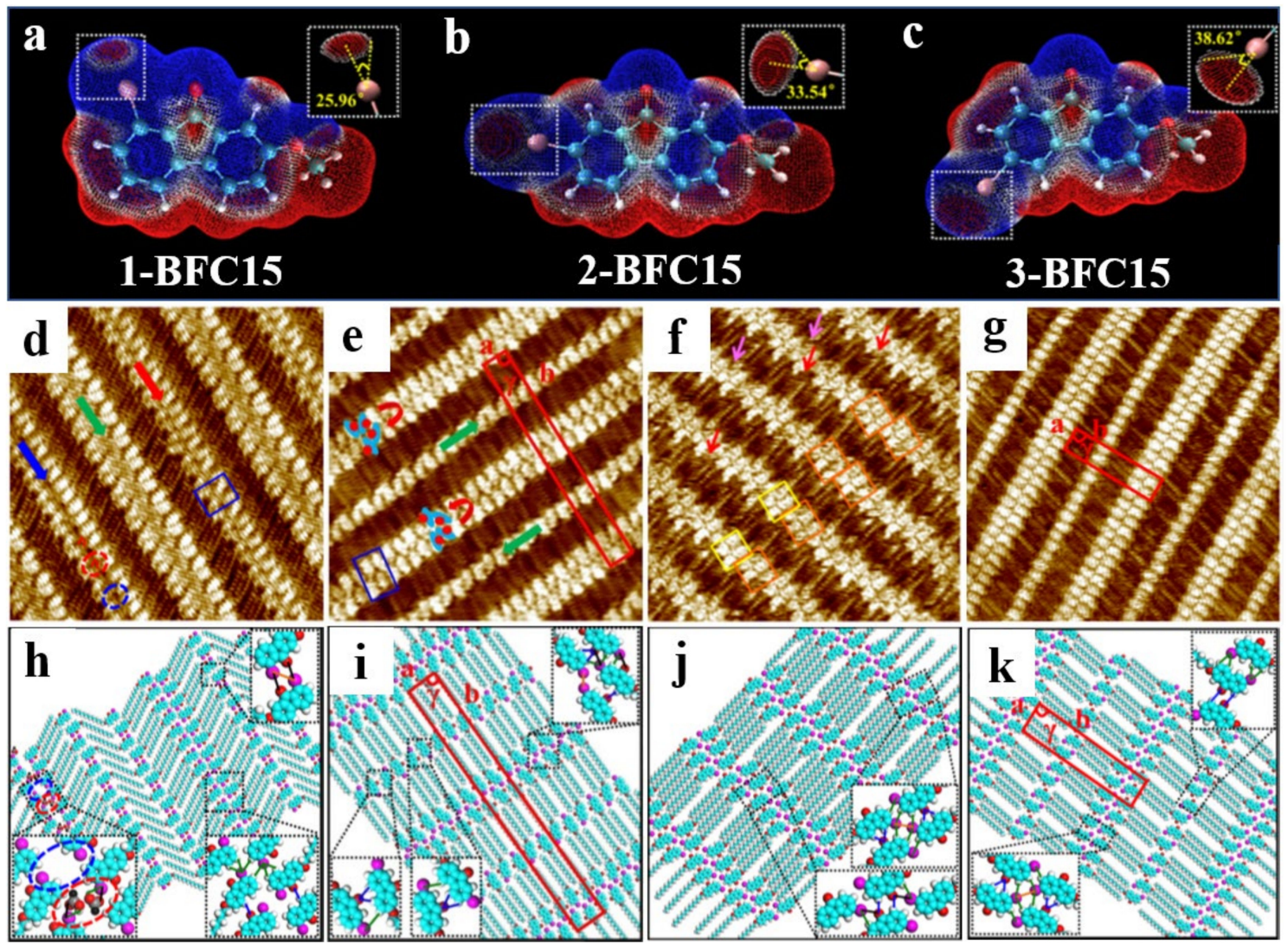

Figure 10. (a-c) Calculated 3D ESP maps of 1-BFC15, 2-BFC15, and 3-BFC15 molecules. (d-g) Highresolution STM images show the self-assembled alternate-I (d, 1-BFC15), alternate-II (e, 2-BFC15), lamellar (f, 3-BFC15), and alternate-III patterns (g, 3-BFC15) at the 1-octanoic acid/HOPG interface, respectively. Scanning areas: $20 \times 20 \mathrm{~nm}^{2}$. (h-k) Proposed molecular models of $(\mathbf{d}-\mathbf{g})$. Intermolecular interactions are reflected in the enlarged insets. Reproduced from [82] with permission from the American Chemical Society.

The lamellar and alternate-III (Figure 10f,g) patterns for 3-BFC15 are observed at high and low concentrations, respectively. In lamellar nanostructure, tetramers and hexamers (indicated by the yellow and orange rectangles in Figure 10f, respectively) are formed, which alternately align along each trough randomly. As the middle-inset shown in Figure 10j, 3-BFC15 molecules on the same side take a parallel style linked by $\mathrm{C}-\mathrm{H} \cdots \mathrm{O}=\mathrm{C}$ and $\mathrm{C}-\mathrm{H} \cdots \mathrm{Br}$ HBs, which connect with the antiparallel molecules on the neighboring side through $\mathrm{C}-\mathrm{H} \cdots \mathrm{Br} \mathrm{HBs}$ and type-I Br$\cdots \mathrm{Br}$ contacts. Whereas, neighboring 
complexes along the troughs are linked by $\mathrm{C}-\mathrm{Br} \cdots \mathrm{O}=\mathrm{C}$ XBs, $\mathrm{C}-\mathrm{H} \cdots \mathrm{O}=\mathrm{C}$, and $\mathrm{C}-\mathrm{H} \cdots \mathrm{Br} \mathrm{HBs}$ (Figure 10j). In the alternate-III pattern (Figure 10g), 3-BFC15 molecules in neighboring rows of the two-row troughs take a head-to-head fashion bonded by $\mathrm{C}-\mathrm{H} \cdots \mathrm{Br} \mathrm{HBs}$ and $\mathrm{Br} \cdots \mathrm{Br}$ type-I contacts. In the one-row troughs, the $\mathrm{C}-\mathrm{H} \cdots \mathrm{O}=\mathrm{C}$ and $\mathrm{C}-\mathrm{H} \cdots \mathrm{Br}$ HBs are formed in and between the dimers, respectively (Figure 10k).

The diverse nanostructures might arise from different positions of bromine substituent in fluorenone derivatives, which can cause various charge distributions of the fluorenone $\pi$-core and adjust the positive charge distribution of the $\sigma$-hole on the $\mathrm{Br}$ atom along the $\mathrm{C}-\mathrm{Br}$ axis. In addition, the distinct arrangements of the two-row troughs are ascribed to the directionality of XBs and the closest packing principle.

Various terminal groups of side chains can influence the self-assembly patterns governed by XBs at the 1-phenyloctane/HOPG interface. Three bromine substituted fluorenone derivatives bearing an alkoxy chain terminated by ethoxycarbonyl, carboxyl, and hydroxyl groups (Scheme 1h and Figure 11a) are used to systematically investigate the terminal group effect on the molecular assembly [83]. $\mathrm{C}-\mathrm{H}$... O-C HBs are formed within the $\pi$-conjugated cores of adjacent molecules in the assembled nanostructure of BEDF. Besides, the cores form dimers by a pair of C-H.Br HBs (Figure 11c,g). Each molecule in dimers interacts with the $\mathrm{COOC}_{2} \mathrm{H}_{5}$-terminated groups of the side chains in the adjacent dimers along the troughs to form $\mathrm{C}-\mathrm{H} \cdot \mathrm{O}-\mathrm{C}\left(\mathrm{COOC}_{2} \mathrm{H}_{5}\right) \mathrm{HBs}$ (Figure $\left.11 \mathrm{~g}\right)$.

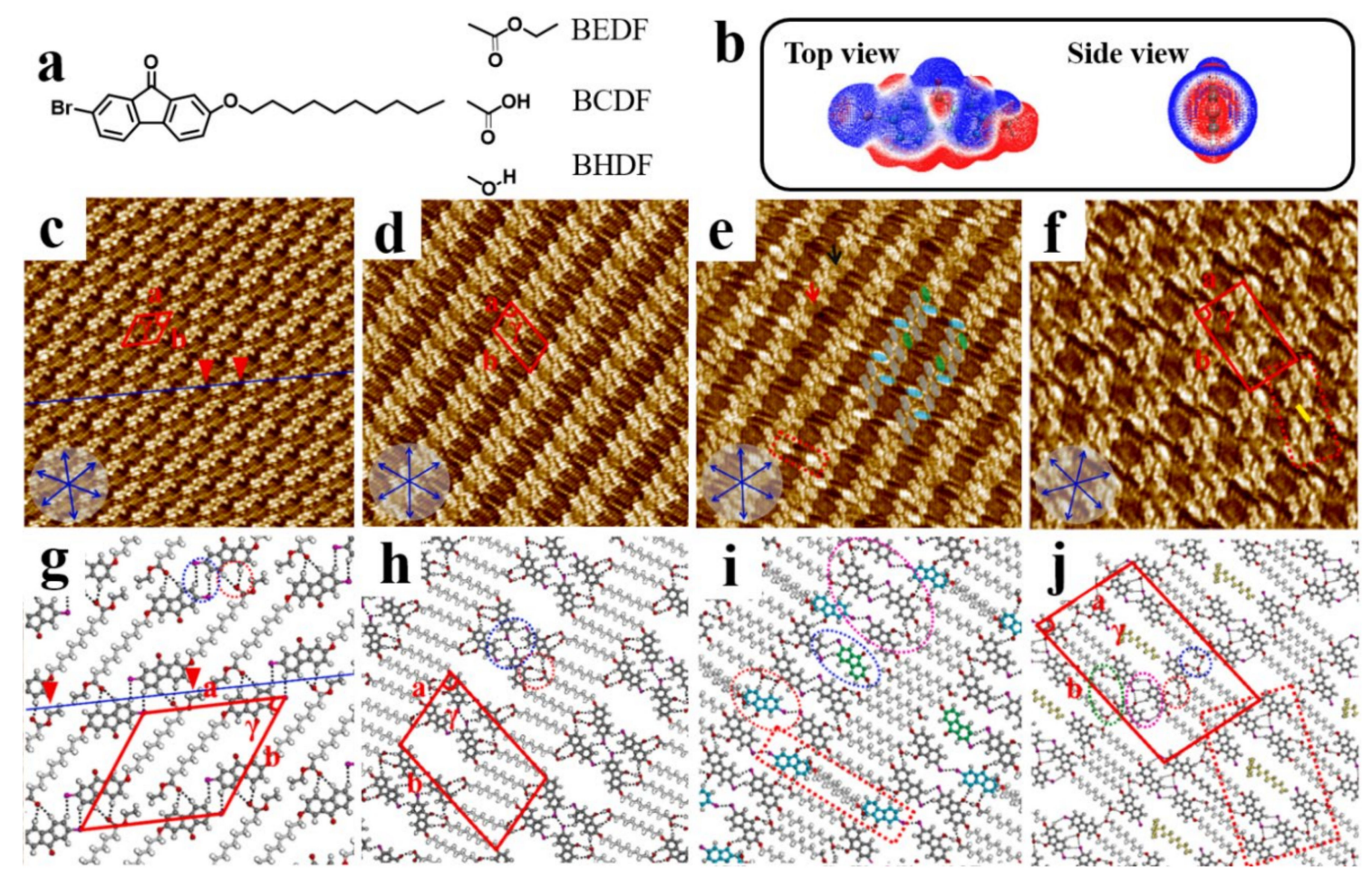

Figure 11. (a) Chemical structures of BEDF, BCDF, and BHDF. (b) Top and side views of the calculated 3D ESP map of Br substituted fluorenone core. (c-f) High-resolution STM images show the self-assembled dimer pattern (BEDF), tetramer pattern (BCDF), lamellar pattern (BHDF) and the octamer pattern (BHDF) at the 1-phenyloctane/HOPG interface, respectively. Scanning areas: $20 \times 20 \mathrm{~nm}^{2}$. (g-j) Proposed molecular models of (c-f). Reproduced from [83] with permission from the Elsevier B. V.

For BCDF molecule, the linear pattern is composed of tetramers (Figure 11d). Four BCDF molecules form an aggregate, serving as the fundamental unit to arrange orderly along the bright troughs. BCDF cores in diagonal within the tetramers are antiparallel and bonded by a type-I Br...Br contact, as well as interact with two adjacent antiparallel cores by $\mathrm{C}-\mathrm{H} \cdot \mathrm{Br}$ HBs (Figure 11h). 
For BHDF molecule, the lamellar and octamer patterns are observed at high concentrations. After continuous scanning, the octamer pattern will transform into the lamellar pattern. Whereas, at low concentrations, only the octamer pattern is observed. The lamellar pattern (Figure 11e) shows that BHDF molecules self-assemble into two-row troughs. Along the two-row troughs, four molecules form a tetramer (Figure 11e), which are adjacent to a dimer marked by the blue and green ellipses. The tetramers are formed by a pair of $\mathrm{C}-\mathrm{H} \cdots \mathrm{Br}$ HBs, while the other antiparallel cores in top-left and bottom-right make no contribution. Neighboring tetramers along the direction of the side chains are interconnected by the interdigitated chains, leading to form four $\mathrm{O}-\mathrm{H} \cdot \cdot \mathrm{O}-\mathrm{C}$ HBs and two additional $\mathrm{C}-\mathrm{H} \cdots \mathrm{O}-\mathrm{H}(\mathrm{OH}) \mathrm{HBs}$. The results reveal that the terminal functional groups play key roles in the regulation of $2 \mathrm{D}$ self-assembly nanostructures and serve as the triggers of XBs.

\subsection{Self-Assembled Patterns of Phenanthrene Derivatives at the Liquid/HOPG Interface}

Tuning the number and position of halogen substituents on the $\pi$-conjugated cores also affects the molecular arrangement on surfaces. The adjustment mechanism is illustrated via alkoxy substituted phenanthrene derivatives [84]. Self-assembled nanostructures of 2,7-DBHP, 3,6-DBHP, and 3-DBHP (Scheme 1i and Figure 12a-c) were observed at the 1-octanoic acid/HOPG interface. Both 2,7-DBHP and 3,6-DBHP could form densely packed columnar networks with edge-on orientation on the surface at relatively higher concentrations. This nanostructure is stabilized by interchain vdW interactions and $\pi-\pi$ stacking between the $\pi$-conjugated cores. At low solution concentrations, the $\pi$-conjugated cores of 2,7-DBHP and 3,6-DBHP molecules adsorb on the HOPG surface with a flat-on fashion (Figure 12d,e). Molecular models for the adlayers of 2,7-DBHP and 3,6-DBHP are proposed, as shown in Figure 12g,h. For 2,7-DBHP, Br atoms tend to form $\mathrm{Br} \cdots \mathrm{O}(\mathrm{COO}) \mathrm{XB}$ with co-absorbated 1-octanoic acid molecules [41], whereas for 3,6-DBHP, three molecules arrange in a head-to-head fashion through type-I $\mathrm{Br} \cdots \mathrm{Br}$ contacts and $\mathrm{H} \cdots \mathrm{Br}$ bonds, which induce the formation of zigzag packing. At moderate concentrations, 2,7-DBHP can form an intermediate pattern, which consists of rows with flat-on and edge-on styled $\pi$-conjugated cores.

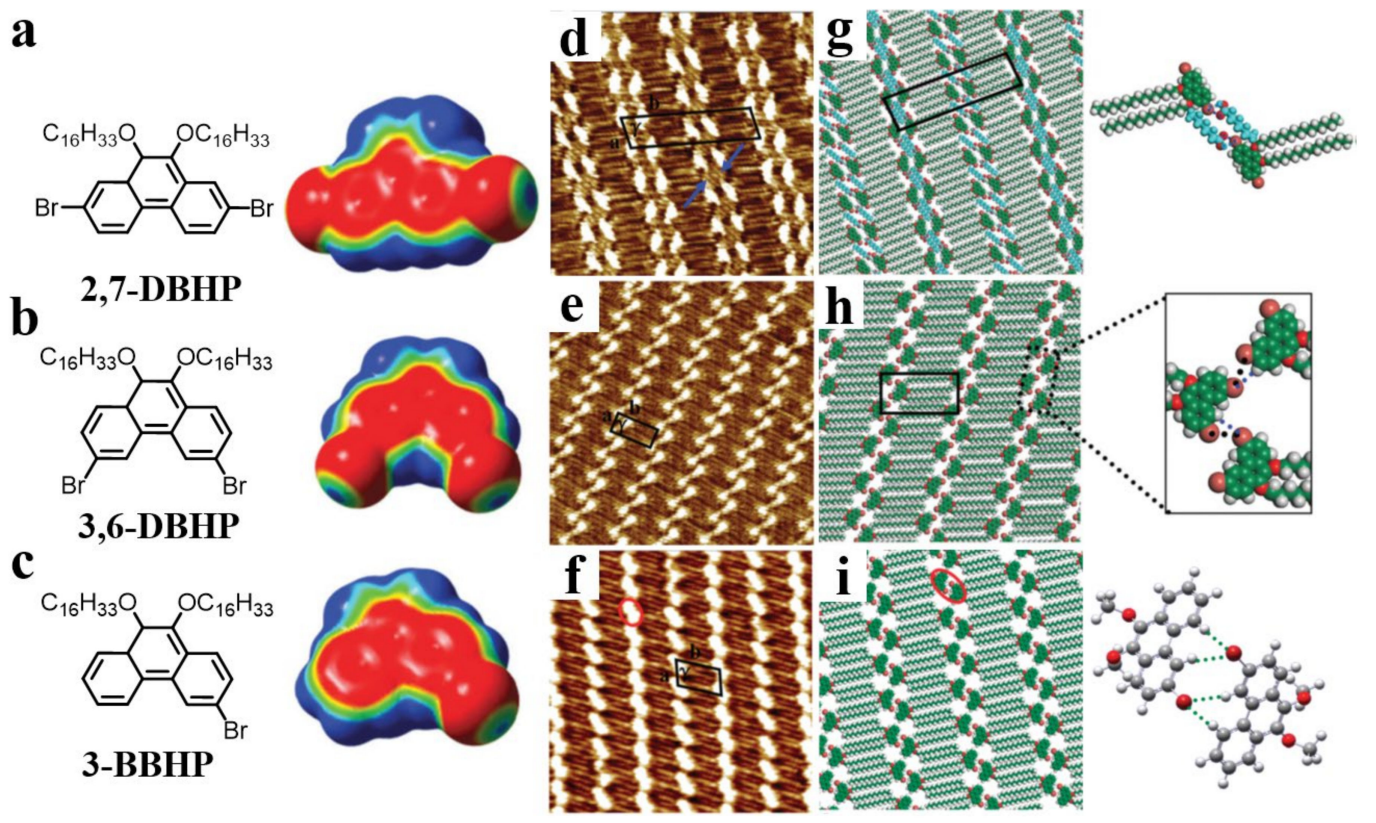

Figure 12. (a-c) Molecular structures and their calculated 3D ESP maps of 2,7-DBHP, 3,6-DBHP, and 3-BBHP, respectively. (d-f) Self-assembled networks formed by 2,7-DBHP, 3,6-DBHP, and 3-BBHP at the 1-octanoic acid/HOPG interface, respectively. Scanning area: $15 \times 15 \mathrm{~nm}^{2}$. (g-i) Proposed molecular models of (d-f). Reproduced from [84] with permission from the Royal Society of Chemistry. 
For 3-BBHP molecules, no solvent and concentration effects are observed in the self-assembly process. The molecules form a dimer with their bromine atoms in an antiparallel style, leading to the formation of two-fold nodes marked by a red circle in Figure 12f,i. The dislocated linear pattern is stabilized by triangular $\mathrm{C}-\mathrm{H} \cdots \mathrm{Br}$ HBs. These results demonstrate that the different positions and numbers of $\mathrm{Br}$ atoms on the phenanthrene cores significantly affect intermolecular interactions and determine the outcome of supramolecular architectures.

\subsection{Self-Assembled Patterns of Phenanthridine Derivatives at the Liquid/HOPG Interface}

Four regioisomeric phenanthridine derivatives with different positions of halogen substituents and alkoxy chains (2,9-BHP, 2,9-BHPO, 3,8-BHP, and 3,8-BHPO) (Scheme 1j and Figure 13a-d) were synthesized in order to investigate the XBs in 2D self-assembled nanostructures by STM at the 1-phenyloctane/HOPG interfaces [85]. For 2,9-BHP and 3,8-BHP molecules, these two molecules form linear structures with the $\pi$-conjugated cores parallel to each other in each lamella (Figure 13i,k). The $\pi$-conjugated cores of 2,9-BHP molecules in neighboring rows pack in a head-to-head style and form a helical arrangement (Figure 13i). The molecular model (Figure 13m) displays that the intermolecular $\mathrm{Br} \cdots \mathrm{N}$ XBs and $\mathrm{H} \cdots \mathrm{Br}$ HBs stabilize the pattern. The arrangement of the $\pi$-conjugated cores for 3,8-BHP molecules has a right-handed rotation (Figure 13k). The stronger intermolecular XBs and HBs are the dominated forces to govern the arrangement of 2,9-BHP and 3,8-BHP molecules in 2D self-assembled adlayers.
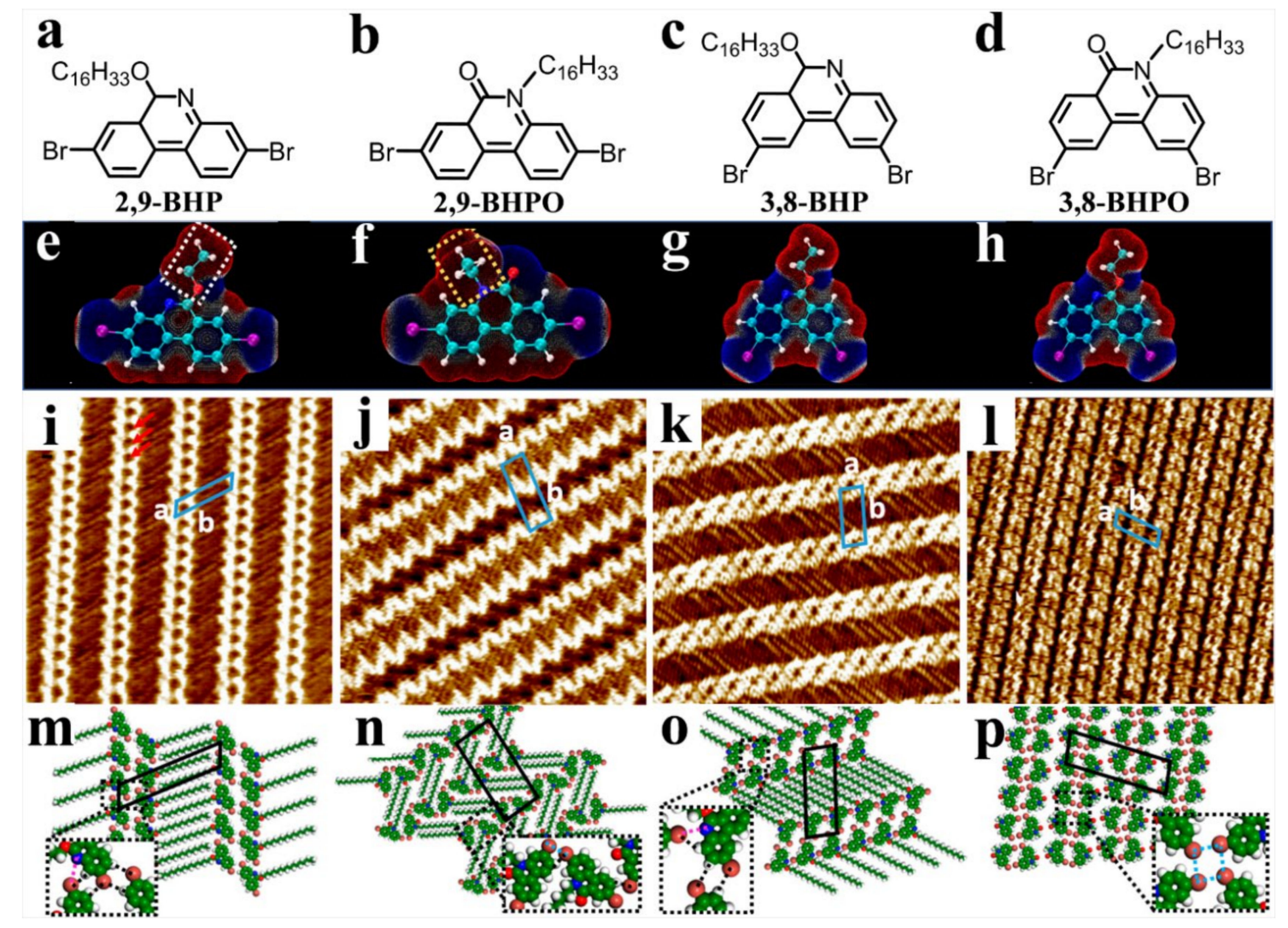

Figure 13. (a-d) Chemical structures of 2,9-BHP, 2,9-BHPO, 3,8-BHP, and 3,8-BHPO and their calculated 3D ESP maps (e-h). (i-1) High-resolution STM images of 2,9-BHP, 2,9-BHPO, 3,8-BHP, and 3,8-BHPO adlayers at the 1-phenyloctane/HOPG interface. $(\mathbf{m}-\mathbf{p})$ Proposed molecular models of $(\mathbf{i}-\mathbf{l})$. Image area: $(\mathbf{i}, \mathbf{j}, \mathbf{l}) 20 \times 20 \mathrm{~nm}^{2} ;(\mathbf{k}) 15 \times 15 \mathrm{~nm}^{2}$. The insets in each model show intermolecular interactions. Pink:

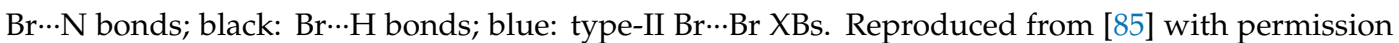
from the American Chemical Society. 
In contrast, 2,9-BHPO forms a zigzag linear pattern (Figure 13j) stabilized by the $\mathrm{H} \cdots \mathrm{Br}$ and $\mathrm{C}-\mathrm{H} \cdots \mathrm{C}=\mathrm{O}$ HBs (Figure 13n); 3,8-BHPO can self-assemble into a lamellar arrangement with all the side chains stretching into the solution (Figure 131). Four $\pi$-conjugated cores of 3,8-BHPO form a tetramer by four type-II Br..Br XBs, which induce the structural formation (Figure 13p). Due to the desorbed side chains in this pattern, the adlayer is not stable on the surface.

The position of the side chain attached to the $\pi$-conjugated cores of molecules also plays a significant role in determining the molecular arrangements. The alkoxy chain can rotate randomly to form dense packing. Whereas, the alkyl chain is rigid, and the $\mathrm{C}-\mathrm{N}$ bond cannot rotate. Therefore, the chain-chain and chain-substrate vdW interactions for four molecules should not be ignored.

\subsection{Self-Assembled Patterns of Thienophenanthrene Derivatives at the Liquid/HOPG Interface}

Self-assembly of thienophenanthrene (TP) derivatives of 6,9-DBTD and 5,10-DBTD (Scheme 1k and Figure $14 \mathrm{a}$ ) with triangle $\pi$-conjugated cores were investigated at the $n$-tridecane/HOPG interface by varying the solution concentration (from $10^{-3}$ to $10^{-6} \mathrm{M}$ ) $[86,87]$. A well-ordered lamellar structure of 6,9-DBTD (Figure 14e) is observed. It is obviously displaying that two TP $\pi$-cores form a dimer and arrange in a head-to-head style through two pairs of type-II Br $\cdots B r$ XBs and $\mathrm{H} \cdots \mathrm{Br}$ bonds, while adjacent dimers are bonded by a pair of $\mathrm{C}-\mathrm{H} \cdots \mathrm{O}-\mathrm{C}$ and $\mathrm{H} \cdots \mathrm{Br}$ HBs. Besides, the side chains arrange in a tail-to-tail style and are vertical to the rows (Figure 14j). When decreasing the solution concentration $\left(1.6 \times 10^{-5} \mathrm{M}\right)$, the co-adsorbed linear pattern of 6,9-DBTD (Figure 14f) is observed. In one row, two TP $\pi$-cores form a dimer via a pair of $\mathrm{C}-\mathrm{H} \cdots \mathrm{O}-\mathrm{C}$ HBs with an antiparallel arrangement, while adjacent

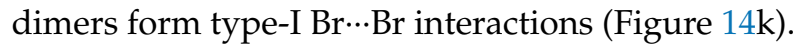
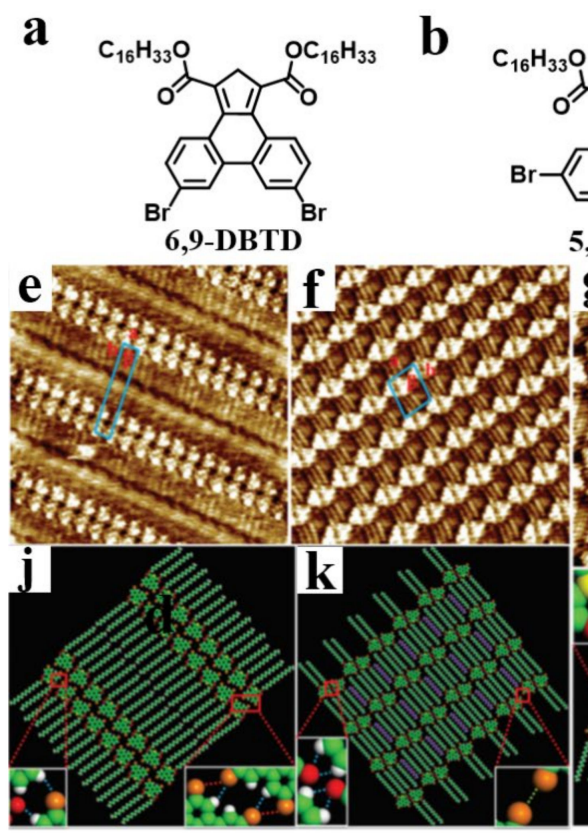

Figure 14. (a-d) Chemical structures of 6,9-DBTD and 5,10-DBTD and their calculated 3D ESP maps. $(\mathbf{e}, \mathbf{f})$ High-resolution STM images show the lamellar structure $\left(1.2 \times 10^{-4} \mathrm{M}\right)$ and co-adsorbed linear pattern $\left(6.2 \times 10^{-5} \mathrm{M}\right)$ of 6,9-DBTD adlayers at the $n$-tridecane/HOPG interface. (g-i) High-resolution STM images showing vertebra-like structure $\left(2.8 \times 10^{-4} \mathrm{M}\right)$, hexagonal network pattern $\left(5.7 \times 10^{-5} \mathrm{M}\right)$, and linear pattern $\left.\left(5.3 \times 10^{-6} \mathrm{M}\right)\right)$ of 5,10-DBTD adlayers at the $n$-tridecane/HOPG interface. Image area: $(\mathbf{e}-\mathbf{g}, \mathbf{i}) 20 \times 20 \mathrm{~nm}^{2}$, (h) $17 \times 17 \mathrm{~nm}^{2}$. (j-n) Proposed structural models of $(\mathbf{e}-\mathbf{i})$. Reproduced from $[86,87]$ with permission from the Royal Society of Chemistry. 
The 5,10-DBTD molecules (Figure 14b) self-assemble into a large organized domain with a vertebra-like pattern (Figure 14g) at a saturation concentration. Two TP $\pi$-cores arrange in a joint-like motif with an angle-to-angle style by intermolecular bifurcated $\mathrm{Br} \cdots \mathrm{O}-\mathrm{C}$ and $\mathrm{Br} \cdots \mathrm{S}$ XBs. The adjacent 5,10-DBTD units are connected via $\mathrm{C}-\mathrm{H} \cdots \mathrm{Br}$ and $\mathrm{C}-\mathrm{H} \cdots \mathrm{O}-\mathrm{C}$ HBs, which further strengthen this motif. Two rows of molecules are packed in an anti-parallel fashion and form the vertebra-like pattern, leading to the minimized polarity of the adlayer [88]. Therefore, 5,10-DBTD exhibits a distinct and nonidentical XB. With decreases in concentration, the hexagonal network of 5,10-DBTD with a 6-fold ring elementary structural motif is encompassed by two pairs of molecules and two single molecules (indicated by triangles) (Figure 14h). Two TP $\pi$-conjugated cores appear in pairs with anti-parallel orientations in dimer via type-I $\mathrm{Br} \cdots \mathrm{Br}$ interactions, marked by triangles with the same color. Besides, the TP $\pi$-cores marked by blue triangles form type-I $\mathrm{Br} \cdots \mathrm{Br}$ contacts with the molecules in the adjacent hexagonal ring (Figure $14 \mathrm{~m}$ ), respectively. When further diluting the concentration $\left(8.2 \times 10^{-5} \mathrm{M}\right)$, the typical STM image of the 5,10-DBTD adlayer shows the formation of a linear pattern (Figure 14i). The molecules take an anti-aligned arrangement, and their side chains stretch into one side of rows and vertical to the rows. Therefore, all the carboxyl group orientations might pack toward the conjugated $\mathrm{TP}$ core formed $\mathrm{Br} \cdots \mathrm{O}-\mathrm{C}$ XBs, which play key roles in determining the structural formation. Besides, the adjacent TP cores are connected via a single type-I $\mathrm{Br} \cdots \mathrm{Br}$ interaction.

The halogen-heteroatom interactions can also tune the formation of 2D supramolecular networks at the liquid/solid interface. The 5,10-DBTD and 5,10-DITD molecules are investigated by combinations of STM observations and DFT calculations [89]. This experiment focuses on how the orientations of the ester substituent for 5,10-DBTD and 5,10-DITD affect positive charge distribution of halogens by DFT, which plays a key role in determining the formation of intermolecular XB and various self-assembled arrangements.

To confirm the formation of $\mathrm{XB}$, different concentrations and substituted halogen atoms ( $\mathrm{Br}$ and I) are adopted. Under saturated solution, a large organized domain with a vertebra-like motif of 5,10-DBTD (Figure 15c) is observed by STM at the 1-phenyloctane/HOPG interface. Two $\pi$-cores of 5,10-DBTD arrange in an infinite joint-like motif through bifurcated $\mathrm{Br} \cdots \mathrm{O}-\mathrm{C}$ and $\mathrm{Br} \cdots \mathrm{S}$ XBs, as the red rectangle indicates in Figure 15c. The 5,10-DBTD molecules are connected by $\mathrm{C}-\mathrm{H} \cdots \mathrm{Br}$ and $\mathrm{C}-\mathrm{H} \cdots \mathrm{O}-\mathrm{C}$ HB interactions, which further reinforce this ribbon pattern (Figure 15c). Because of the alkyl substitution in aromatic compounds with halogen atoms, the $\mathrm{XBs}$ and vdW forces dominate the formation of a self-assembled network on the HOPG surface. In this arrangement, the orientation of the side chains directly determines the orientation of carboxyl, leading to the formation of intermolecular $\mathrm{Br} \cdots \mathrm{O}-\mathrm{C}$ XBs. The direction of $\mathrm{Br} \cdots \mathrm{S}$ XB is along the $\mathrm{C}-\mathrm{Br}$ bond toward the positive charge region of the sulfur atom $[70,90]$. Thus, 5,10-DBTD exhibits distinct and nonidentical XBs that vary as a function of halogen identity. With decreasing solution concentration, an alternate vertebra-like structure is formed (Figure 15d), in which all the carboxyl groups orient to the $\pi$-conjugated cores (Figure 15h). The $\mathrm{Br} \cdots \mathrm{O}-\mathrm{C}$ XBs play significant roles in controlling the formation of this pattern, except for the interchain vdW interactions.

When substituted halogen atoms are changed from a $\mathrm{Br}$ atom to an I atom, 5,10-DITD forms a honeycomb-like network composed of two zigzag lines (Figure 15e) at a saturated concentration. In each line, all the $\pi$-conjugated cores of 5,10-DITD arrange in an angle-to-angle style by successive intermolecular bifurcated I...O-C and I...S XBs (Figure 15i). All the side chains stretch into different directions. With further decreases in the solution concentration, an alternate-I pattern is formed (Figure 15f). The molecular packing in the zigzag line is the same as that in the honeycomb-like pattern. In the dimers, the side chains have the same stretching direction as those in the zigzag structure (Figure 15j), indicating that only the type-I I...I contact bond is formed. This work gives a deep insight into the role of ester orientation and concentration on the formation of halogen-heteroatom contacts, which proves relevant for identification of multiple XBs in 2D crystal engineering. 
a
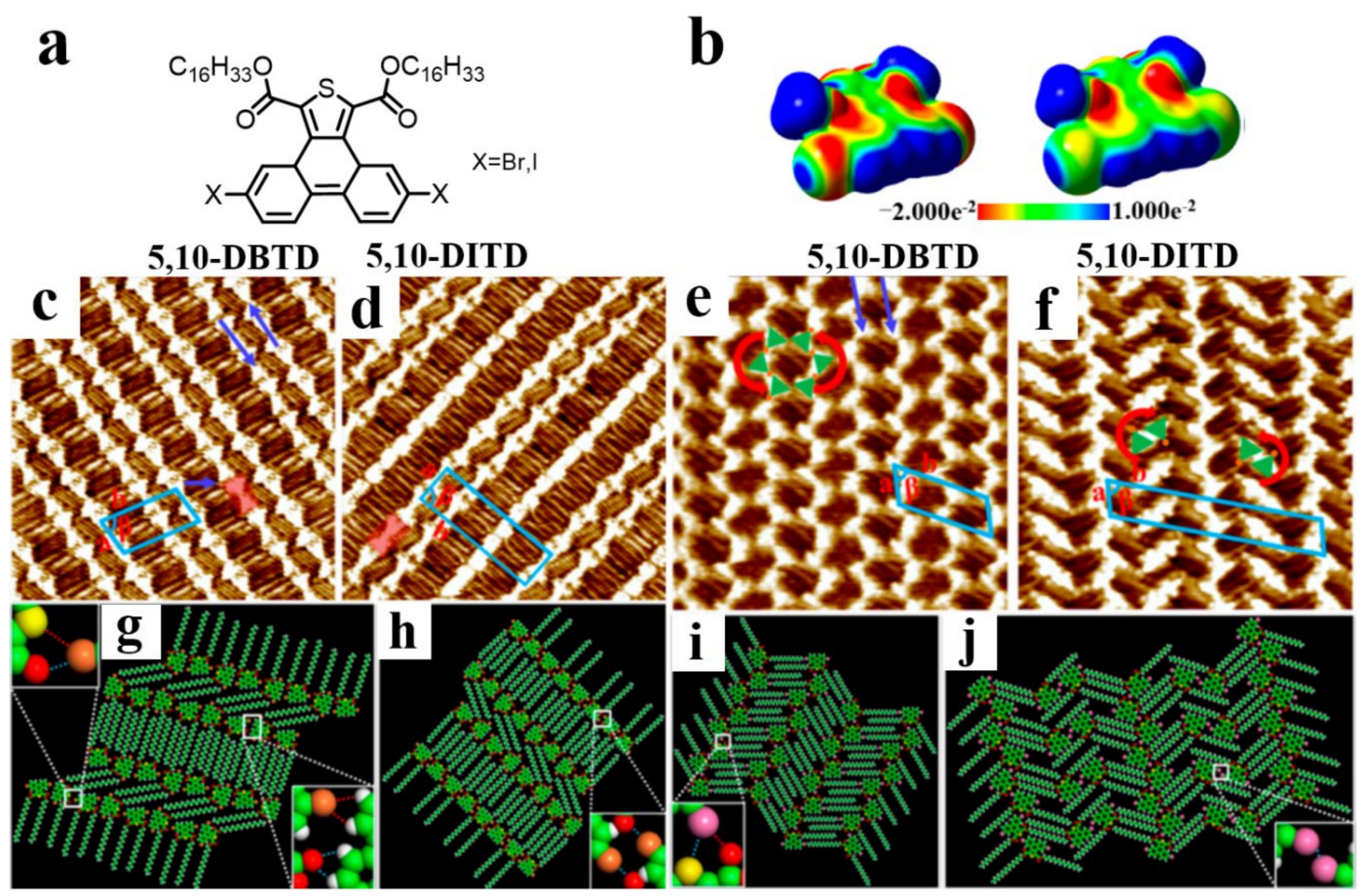

Figure 15. (a,b) Chemical structures of 5,10-DBTD and 5,10-DITD, and their calculated 3D ESP maps. (c,d) High-resolution STM images of vertebra-like $\left(2.5 \times 10^{-4} \mathrm{M}\right)$ and alternate vertebra-like $\left(9.7 \times 10^{-5} \mathrm{M}\right)$ patterns of 5,10-DBTD adlayers at the 1-phenyloctane/HOPG interface, respectively. $(\mathbf{e}, \mathbf{f})$ High-resolution STM images of honeycomb-like $\left(6.6 \times 10^{-4} \mathrm{M}\right)$ and alternate chiral $\left(8.2 \times 10^{-5} \mathrm{M}\right)$ patterns of 5,10-DBTD adlayers at the 1-phenyloctane/HOPG interface, respectively. Scanning area: $20 \times 20 \mathrm{~nm}^{2}$. (g-j) Proposed structural models of $(\mathbf{c}-\mathbf{f})$. Insets show the intermolecular interactions. Reproduced from [89] with permission from the American Chemical Society.

In addition, the concentration-dependent self-assembly of 5,10-DITD was investigated at the 1-octanic acid/graphite interface by STM [91]. Three chiral arrangements and 2D assembled structural transformation mainly controlled by XBs are clearly revealed. At high concentrations, the molecules self-assemble into a honeycomb-like chiral network (Figure 16c,d). Except for the interchain vdW forces, this nanostructure is stabilized by intermolecular continuous $\mathrm{C}-\mathrm{O} \cdots \mathrm{I} \cdots \mathrm{S}$ XBs in each zigzag line. At a

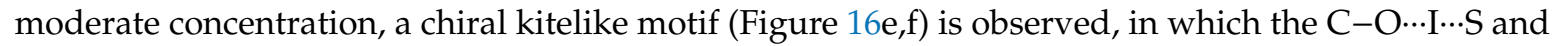
$\mathrm{I} \cdots \mathrm{O}-\mathrm{C}$ XBs, along with the molecule-solvent $\mathrm{C}-\mathrm{O} \cdots \mathrm{I} \cdots \mathrm{H}$ XBs are the dominated forces to determine the structural formation. At low concentrations, the molecules form a chiral cyclic network (Figure 16g,h) by molecule-molecule $\mathrm{C}-\mathrm{O} \cdots \mathrm{I} \cdots \mathrm{S}$ XBs and molecule-solvent $\mathrm{C}-\mathrm{O} \cdots \mathrm{I} \cdots \mathrm{H}$ XBs. The above results reveal that the type of intermolecular XBs and the number of the co-adsorbed 1-octanic acids determine the formation and transformation of chirality.

Based on the TP core, an asymmetric M1 molecule (Figure 17a) was designed and synthesized to investigate $\mathrm{C}-\mathrm{Br} \cdots \pi \mathrm{XB}$-induced molecular self-assembly at the $n$-hexadecane/solid interface [92]. According to the self-adaption principle of molecule geometry in 2D supramolecular self-assembly, three types of self-assembly dimers are predicted (Figure 17c), which are confirmed by STM experiment and DFT calculations. Three nanostructures ("N" type, "tail-to-tail", and discrete structures) are observed by continually decreasing concentrations (Figure $17 \mathrm{~d}, \mathrm{f}, \mathrm{h}$ ). Among the three nanostructures, the relative location of two molecular cores in dimer I is maintained, and the difference is only in the arrangement of alkoxy chains. The results demonstrate that dimer I not only has a high binding energy derived from the collaboration of $\mathrm{C}-\mathrm{H} \cdots \mathrm{Br} \cdots \pi$ bonds and the rigid directionality of $\mathrm{C}-\mathrm{Br} \cdots \pi$ $\mathrm{XBs}$, but also has support from vdW forces generated from the suitable lengths of the side chains and $n$-hexadecane molecules. 


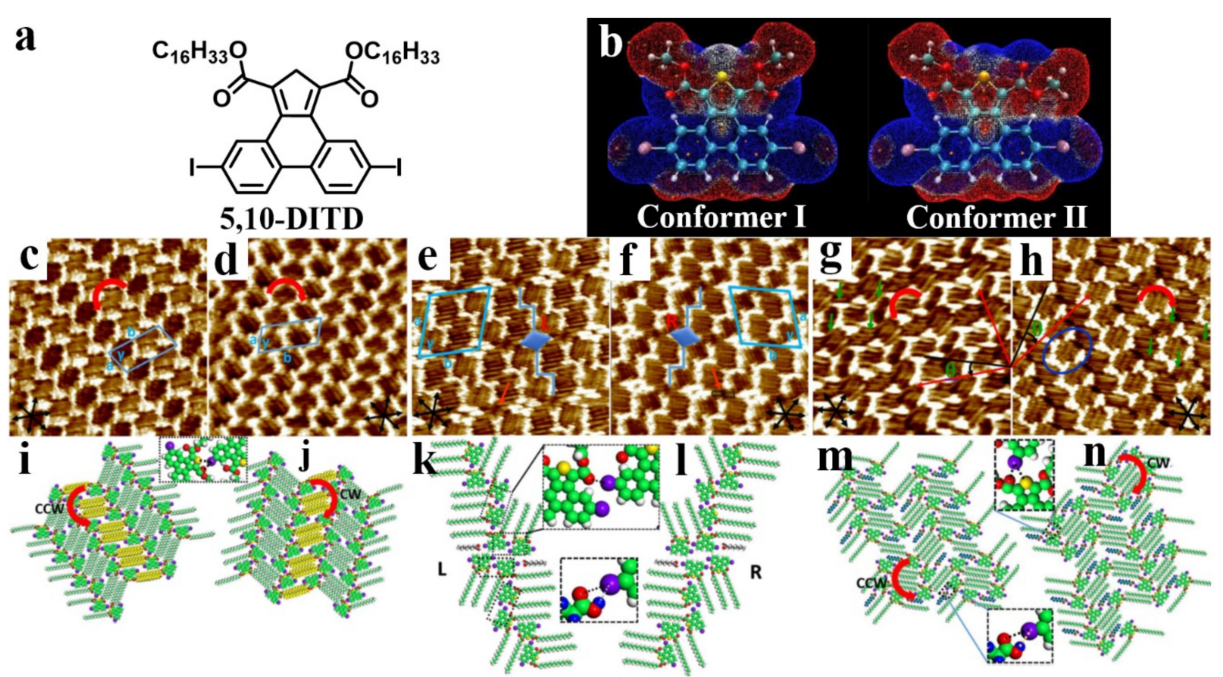

Figure 16. (a) Chemical structure of 5,10-BITD. (b) Calculated 3D charge density maps of 5,10-DITD with different configurations of ester groups. (c-h) High-resolution STM images of CCW and CW honeycomb-like, kite-like, and cyclic networks formed by 5,10-DITD at the 1-octanic acid/HOPG interface $\left(2.0 \times 10^{-3} \mathrm{M} ; 5.0 \times 10^{-4} \mathrm{M} ; 5.0 \times 10^{-5} \mathrm{M}\right.$; scanning area: $\left.20 \times 20 \mathrm{~nm}^{2}\right)$. (i-n) Proposed molecular models of (c-h) showing R and L kite-like, kite-like, and cyclic networks. Reproduced from [91] with permission from Elsevier B.V.
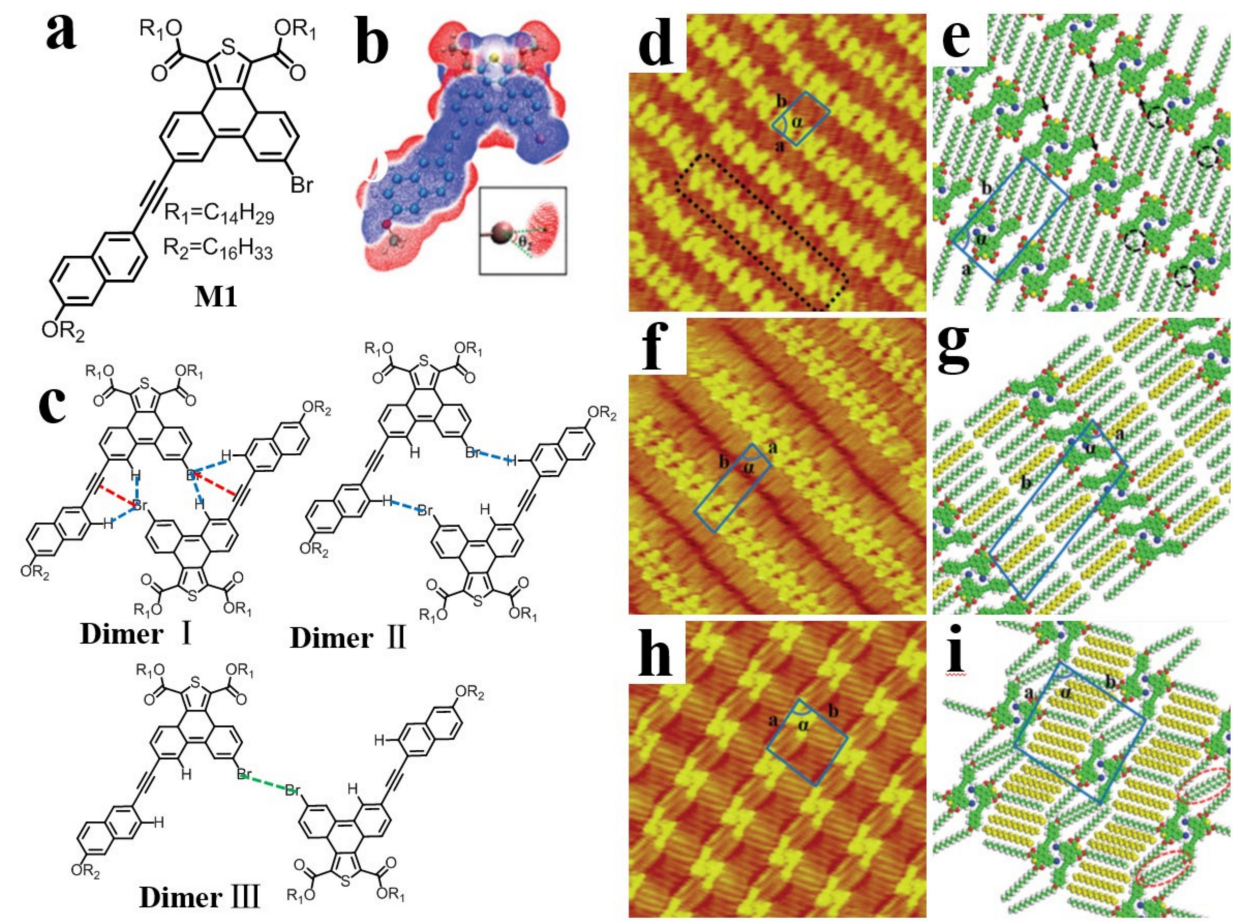

Figure 17. (a) Chemical structure of M1. (b) Calculated 3D ESP map of the M1 conjugated core.

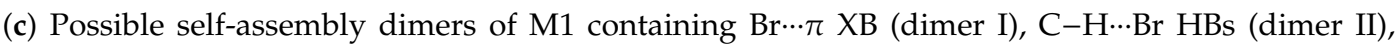

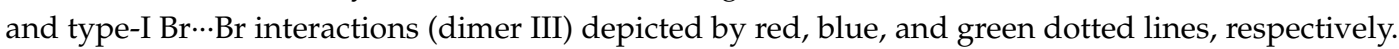
(d) A high-resolution STM image of the linear structure consisted of dimer I at the $n$-hexadecane/HOPG interface. Some dimer II structures are excluded by the black dotted rectangle. (f,h) High-resolution STM images showing the "tail-to-tail" and discrete structures, respectively. (e-i) Proposed structural models of $(\mathbf{d}, \mathbf{f}, \mathbf{h})$. Image size: $20 \times 20 \mathrm{~nm}^{2}$. Reproduced from [92] with permission from the Royal Society of Chemistry. 
Generally, changing the shape of the molecular $\pi$-conjugate core and varying the position, type, and number of halogen substituents of the molecules could modify the intermolecular interactions. The results indicate that these methods are efficient to further investigate XBs on surfaces, and these factors play significant roles in controlling the arrangement of nanostructures.

\section{Conclusions}

This review briefly documented the definition, research history, and essential properties of the XBs. The $\mathrm{XB}$, as a "specific supramolecular interaction" has been widely used in the preparation of complex 2D self-assembly motifs. This review includes 28 molecules that were designed and home-synthesized carefully, and which were grouped by the similarity of $\pi$-conjugated cores. Those molecules within the same family are designed by changing the position and number of the halogen substituents on the aromatic conjugated cores and are used to explore the formation of XBs under different solvents and concentrations at the liquid/solid interface. STM observation and DFT calculations show that an X-X contact often is accompanied by a concomitant $\mathrm{HB}$, and the two bonds act as the collaborative forces to stabilize the 2D adlayers. Moreover, varying the type, number and position of halogen substitutes on the $\pi$-conjugated cores can induce the rearrangement of the electronic density distribution of the molecules, which can give rise to new molecular arrangements on surfaces. However, to confirm the fabrication of networks driven by XBs, significant efforts need to be involved in the design of 2D crystal engineering. Furthermore, the dominant force of molecule-substrate interactions on the formation of self-assembled nanostructures is difficult to quantify in terms of the real contribution of XBs for stabilizing the supramolecular networks. Fortunately, the high-resolution STM images could support precise determination of interatomic distances (bond length) and angles (bond angle), which thus allows better insight into $\mathrm{XBs}$ and $\mathrm{X}-\mathrm{X}$ interactions.

Author Contributions: Writing—original draft preparation, Y.W.; writing—review and editing, X.M.; supervision, W.D. All authors have read and agreed to the published version of the manuscript.

Funding: This research was funded by the Natural Science Foundation of Guangdong Province grant number 2018A030313452, the Science and Technology Program of Guangzhou grant number 202002030083, and the Fundamental Research Funds for the Central Universities (SCUT).

Acknowledgments: Financial support from the Natural Science Foundation of Guangdong Province (2018A030313452), the Science and Technology Program of Guangzhou (202002030083), and the Fundamental Research Funds for the Central Universities (SCUT) is gratefully acknowledged.

Conflicts of Interest: The authors declare no conflict of interest.

\section{References}

1. Desiraju, G.R.; Ho, P.S.; Kloo, L.; Legon, A.C.; Marquardt, R.; Metrangolo, P.; Politzer, P.; Resnati, G.; Rissanen, K. Definition of the Halogen Bond. Pure Appl. Chem. 2013, 85, 1711-1713. [CrossRef]

2. Murray, J.S.; Lane, P.; Politzer, P. Expansion of the $\sigma$-hole concept. J. Mol. Model. 2009, 15, 723-729. [CrossRef] [PubMed]

3. Politzer, P.; Murray, J.S.; Clark, T. Halogen bonding and other $\sigma$-hole interactions: A perspective. Phys. Chem. Chem. Phys. 2013, 15, 11178-11189. [CrossRef] [PubMed]

4. Cavallo, G.; Metrangolo, P.; Milani, R.; Pilati, T.; Priimagi, A.; Resnati, G.; Terraneo, G. The Halogen Bond. Chem. Rev. 2016, 116, 2478-2601. [CrossRef]

5. Colin, M.M.; Gaultier de Claubry, H. Sur Le Combinaisons de L'iode Avec Les Substances Végétales et Animales. Ann. Chim. 1814, 90, 87-100.

6. Guthrie, F. Xxviii.-On the Iodide of Iodammonium. J. Chem. Soc. 1863, 16, 239-244. [CrossRef]

7. Remsen, I.; Norris, J.F. Action of the Halogens on the Methylamines. Am. Chem. J. 1896, 18, 90-95.

8. Ault, B.S.; Andrews, L. Infrared and Raman spectra of the $\mathrm{M}+\mathrm{F}^{3-}$ ion pairs and their mixed chlorine-fluorine counterparts in solid argon. Inorg. Chem. 1977, 8, 2024-2028. [CrossRef]

9. Ault, B.S.; Andrews, L. Matrix reactions of alkali metal fluoride molecules with fluorine. infrared and raman spectra of the trifluoride ion in the $\mathrm{M}+\mathrm{F}^{3-}$ species. J. Am. Chem. Soc. 1976, 98, 1591-1593. [CrossRef] 
10. Riedel, S.; Köchner, T.; Andrews, P.L.; Wang, X. Polyfluoride Anions, a Matrix-Isolation and Quantum-Chemical Investigation. Inorg. Chem. 2010, 41, 7156-7164. [CrossRef]

11. Legon, A.C. Prereactive complexes of dihalogens $x y$ with lewis bases $b$ in the gas phase: A systematic case for the halogen analogue $\mathrm{b}$ small middle dot small middle dot small middle dotxy of the hydrogen bond $\mathrm{b}$ small middle dot small middle dot small middle dotHX. Angew. Chem. Int. Ed. 1999, 38, 2686-2714. [CrossRef]

12. Brinck, T.; Jane, S.; Politzer, P. Surface electrostatic potentials of halogenated methanes as indicators of directional intermolecular interactions. Int. J. Quantum Chem. 1992, 44, 57-64. [CrossRef]

13. Brinck, T.; Murray, J.S.; Politzer, P. Molecular surface electrostatic potentials and local ionization energies of group v-vii hydrides and their anions: Relationships for aqueous and gas-phase acidities. Int. J. Quantum Chem. 1993, 48, 73-88. [CrossRef]

14. Murray, J.S.; Paulsen, K.; Politzer, P. Molecular surface electrostatic potentials in the analysis of non-hydrogen-Bonding noncovalent Interactions. Proc. Indian Acad. Sci. Chem. Sci. 1994, 106, 267-275.

15. Clark, T.; Hennemann, M.; Murray, J.S.; Politzer, P. Halogen bonding: The $\sigma$-hole. J. Mol. Model. 2007, 13, 291-296. [CrossRef] [PubMed]

16. Yamamoto, H.M.; Yamaura, J.I.; Kato, R. Structural and electrical properties of (BEDT-TTF)2X(diiodoacetylene) $(\mathrm{X}=\mathrm{Cl}, \mathrm{Br})$ : The novel self-assembly of neutral Lewis-acidic molecules and halide anions in a molecular metal. J. Mater. Chem. 1998, 8, 15-16. [CrossRef]

17. Maginn, S.J. Crystal engineering: The design of organic solids by G. R. Desiraju. J. Appl. Crystallogr. 1991, 24, 265. [CrossRef]

18. Desiraju, G.R. Supramolecular synthons in crystal engineering-a new organic synthesis. Angew. Chem. Int. Ed. 2010, 34, 2311-2327. [CrossRef]

19. Moulton, B.; Zaworotko, M.J. From molecules to crystal engineering: Supramolecular isomerism and polymorphism in network solids. Chem. Rev. 2001, 101, 1629-1658. [CrossRef] [PubMed]

20. Subramanian, S.; Zaworotko, M.J. Exploitation of the hydrogen bond: Recent developments in the context of crystal engineering. Coord. Chem. Rev. 1994, 137, 357-401. [CrossRef]

21. Atwood, J.L.; Lehn, J.M. Comprehensive supramolecular chemistry. solid-state supramolecular chemistry. Cryst. Eng. 1996, 6, 199-206.

22. Tabellion, F.M.; Seidel, S.R.; Arif, A.M.; Stang, P.J. Discrete supramolecular architecture vs. crystal engineering: The rational design of a platinum-based bimetallic assembly with a chair like structure and its infinite, copper analogue. J. Am. Chem. Soc. 2001, 123, 7740-7741. [CrossRef] [PubMed]

23. Xia, C.; Fan, X.; Locklin, J.; Advincula, R.C.; Gies, A.; Nonidez, W. Characterization, supramolecular assembly, and nanostructures of thiophene dendrimers. J. Am. Chem. Soc. 2004, 126, 8735-8743. [CrossRef] [PubMed]

24. Cook, T.R.; Zheng, Y.R.; Stang, P.J. Metal-organic frameworks and self-assembled supramolecular coordination complexes: Comparing and contrasting the design, synthesis, and functionality of metal-organic materials. Chem. Rev. 2013, 113, 734-777. [CrossRef]

25. Li, H.L.; Eddaoudi, M.M.; O'Keeffe, M.; Yaghi, O.M. Design and synthesis of an exceptionally stable and highly porous metal-organic framework. Nature 1999, 402, 276-279. [CrossRef]

26. Kovbasyuk, L.; Krämer, R. Allosteric supramolecular receptors and catalysts. Chem. Rev. 2004, 104, 3161-3187. [CrossRef]

27. Yan, X.; Wang, F.; Zheng, B.; Huang, F. Stimuli-responsive supramolecular polymeric materials. Chem. Soc. Rev. 2012, 41, 6042-6065. [CrossRef]

28. Sangeetha, N.M.; Maitra, U. Supramolecular gels: Functions and uses. Chem. Soc. Rev. 2005, 34, 821-836. [CrossRef]

29. Buerkle, L.E.; Rowan, S.J. Supramolecular gels formed from multi-component low molecular weight species. Chem. Soc. Rev. 2012, 41, 6089-6102. [CrossRef]

30. Aida, T.; Meijer, E.W.; Stupp, S.I. Functional supramolecular polymers. Science 2012, 335, 813-817. [CrossRef]

31. Stupp, S.I.; Hartgerink, J.D.; Beniash, E. Self-assembly and mineralization of peptide-amphiphile nanofibers. Science 2001, 294, 1684-1688.

32. Gui, S.; Huang, Y.; Zhu, Y.; Jin, Y.; Rui, Z. Biomimetic sensing system for tracing $\mathrm{pb}^{2+}$ distribution in living cells based on the metal-peptide supramolecular assembly. ACS Appl. Mater. Interfaces 2019, 11, 5804-5811. [CrossRef] [PubMed] 
33. Shah, V.B.; Ferris, C.; Orf, G.; Kavadiya, S.; Ray, J.R.; Jun, Y.S.; Lee, B.; Blankenship, R.E.; Biswas, P. Supramolecular self-assembly of bacteriochlorophyll c molecules in aerosolized droplets to synthesize biomimetic chlorosomes. J. Photochem. Photobiol. B 2018, 185, 161-168. [CrossRef] [PubMed]

34. Sanjeeva, K.B.; Pigliacelli, C.; Gazzera, L.; Dichiarante, V.; Bombelli, F.B.; Metrangolo, P. Halogen bond-assisted self-assembly of gold nanoparticles in solution and on a planar surface. Nanoscale 2019, 11, 18407-18415. [CrossRef] [PubMed]

35. Shirman, T.; Arad, T.; van der Boom, M.E. Halogen bonding: A supramolecular entry for assembling nanoparticles. Angew. Chem. Int. Ed. 2010, 49, 926-929. [CrossRef] [PubMed]

36. Bent, H.A. Structural chemistry of donor-acceptor interactions. Chem. Rev. 1968, 68, 587-648. [CrossRef]

37. Braga, D.; Grepioni, F.; Desiraju, G.R. Crystal engineering and organometallic architecture. Chem. Rev. 1998, 98, 1375-1406. [CrossRef]

38. Aakery, C.B.; Champness, N.R.; Janiak, C. Recent advances in crystal engineering. CrystEngComm 2009, 12, 22-43. [CrossRef]

39. Cannon, A.S.; Warner, J.C. Noncovalent derivatization: Green chemistry applications of crystal engineering. Cryst. Growth Des. 2002, 2, 255-257. [CrossRef]

40. Teyssandier, J.; Mali, K.S.; De Feyter, S. Halogen bonding in two-dimensional crystal engineering. ChemistryOpen 2020, 9, 225-241. [CrossRef]

41. Aakery, C.B.; Panikkattu, S.; Chopade, P.D.; Desper, J. Competing hydrogen-bond and halogen-bond donors in crystal engineering. CrystEngComm 2013, 15, 3125-3136. [CrossRef]

42. Messina, M.T.; Metrangolo, P.; Panzeri, W.; Ragg, E.; Resnati, G. Perfluorocarbon-hydrocarbon self-assembly. part 3. liquid phase interactions between perfluoroalkylhalides and heteroatom containing hydrocarbons. Tetrahedron Lett. 1998, 39, 9069-9072. [CrossRef]

43. Metrangolo, P.; Meyer, F.; Pilati, T.; Resnati, G.; Terraneo, G. Halogen bonding in supramolecular chemistry. Angew. Chem. Int. Ed. 2010, 47, 6114-6127. [CrossRef] [PubMed]

44. Metrangolo, P.; Murray, J.S.; Pilati, T.; Politzer, P.; Resnati, G.; Terraneo, G. Fluorine-centered halogen bonding: A factor in recognition phenomena and reactivity. Cryst. Growth Des. 2011, 11, 4238-4246. [CrossRef]

45. Metrangolo, P.; Murray, J.S.; Pilati, T.; Politzer, P.; Resnati, G.; Terraneo, G. The fluorine atom as a halogen bond donor, viz. a positive site. CrystEngComm 2011, 13, 6593-6896. [CrossRef]

46. Politzer, P.; Murray, J.S.; Clark, T. Halogen bonding: An electrostatically-driven highly directional noncovalent interaction. Phys. Chem. Chem. Phys. 2010, 12, 7748-7757. [CrossRef]

47. Mitzel, N.W.; Blake, A.J.; Rankin, D.W.H. Beta-donor bonds in sion units: An inherent structure-determining property leading to (4+4)-coordination in tetrakis-(n,n-dimethylhydroxylamido)silane. J. Am. Chem. Soc. 1997, 119, 4143-4148. [CrossRef]

48. Hennemann, M.; Murray, J.S.; Politzer, P.; Riley, K.E.; Clark, T. Polarization-induced $\sigma$-holes and hydrogen bonding. J. Mol. Model. 2012, 18, 2461-2469. [CrossRef]

49. Politzer, P.; Murray, J.S. A unified view of halogen bonding, hydrogen bonding and other $\sigma$-hole interactions. In Noncovalent Forces; Scheiner, S., Ed.; Springer: Cham, Switzerland, 2015; Volume 19, pp. 291-321.

50. Murray, J.S.; Politzer, P. Hydrogen bonding: A coulombic $\sigma$-hole interaction. J. Indian Inst. Sci. 2020, 100, 21-30. [CrossRef]

51. Sakurai, T.; Sundaralingam, M.; Jeffrey, G.A. A nuclear quadrupole resonance and X-ray study of the crystal structure of 2,5-dichloroaniline. Acta Crystallogr. 2010, 16, 354-363. [CrossRef]

52. Desiraju, G.R.; Parthasarathy, R. The nature of halogen ‥halogen interactions: Are short halogen contacts due to specific attractive forces or due to close packing of non-spherical atoms? J. Am. Chem. Soc. 1989, 111, 8725-8726. [CrossRef]

53. Silly, F.; Viala, C.; Bonvoisin, J. Two-dimensional halogen-bonded porous self-assembled nanoarchitectures of copper $\beta$-diketonato complexes. J. Phys. Chem. C 2018, 122, 17143-17148. [CrossRef]

54. Chang, M.H.; Jang, W.J.; Lee, M.W.; Jeon, U.S.; Han, S.; Kahng, S.J. Networks of non-planar molecules with halogen bonds studied using scanning tunneling microscopy on Au (111). Appl. Surf. Sci. 2018, 432, 110-114. [CrossRef]

55. Silly, F.; Shaw, A.Q.; Castell, M.R.; Briggs, G.A.D. A chiral pinwheel supramolecular network driven by the assembly of ptcdi and melamine. Chem. Commun. 2008, 1907-1909. [CrossRef] [PubMed] 
56. Dai, H.; Wang, S.; Hisaki, I.; Nakagawa, S.; Ikenaka, N.; Deng, K.; Xiao, X.; Zeng, Q.D. On-surface self-assembly of a c 3-symmetric $\pi$-conjugated molecule family studied by STM: Two-dimensional nanoporous frameworks. Chem. Asian J. 2017, 5, 2558-2564. [CrossRef] [PubMed]

57. Qiu, X.; Chen, W.; Zeng, Q.; Bo, X.; Bai, C. Alkane-assisted adsorption and assembly of phthalocyanines and porphyrins. J. Am. Chem. Soc. 2000, 122, 5550-5556. [CrossRef]

58. Silly, F. Selecting two-dimensional halogen-halogen bonded self-assembled 1,3,5-tris(4-iodophenyl)benzene porous nanoarchitectures at the solid-liquid interface. J. Phys. Chem. C 2013, 117, 20244-20249. [CrossRef]

59. Peyrot, D.; Silly, F. On-surface synthesis of two-dimensional covalent organic structures versus halogen-bonded self-assembly: Competing formation of organic nanoarchitectures. ACS Nano 2016, 10, 5490-5498. [CrossRef]

60. Gatti, R.; Macleod, J.M.; Lipton-Duffin, J.A.; Moiseev, A.G.; Perepichka, D.F.; Rosei, F. Substrate, Molecular structure, and solvent effects in 2 d self-assembly via hydrogen and halogen bonding. J. Phys. Chem. C 2014, 118, 25505-25516. [CrossRef]

61. Cavallo, G.; Metrangolo, P.; Pilati, T.; Resnati, G.; Terraneo, G. Halogen bond: A long overlooked interaction. In Halogen Bonding I. Topics in Current Chemistry; Metrangolo, P., Resnati, G., Eds.; Springer: Cham, Switzerland, 2014; Volume 358, pp. 1-17.

62. Binnig, G.; Rohrer, H. The scanning tunneling microscope. Sci. Am. 1985, 253, 50-56. [CrossRef]

63. Park, S.I.; Quate, C.F. Scanning tunneling microscope. Rev. Sci. Instrum. 1987, 58, 2010-2017. [CrossRef]

64. Goronzy, D.P.; Ebrahimi, M.; Rosei, F.; Arramel; Fang, Y.; De Feyter, S.; Tait, S.L.; Perepichka, D.F. Supramolecular assemblies on surfaces: Nanopatterning, functionality, and reactivity. ACS Nano 2018, 12, 7445-7481. [CrossRef] [PubMed]

65. Mate, E. Scientific Conferences: A big hello to halogen bonding. Nat. Chem. 2014, 6, 762-764.

66. Xing, L.; Jiang, W.; Huang, Z.; Liu, J.; Song, H.; Zhao, W.; Dai, J.; Zhu, H.; Wang, Z.; Weiss, P.S. Steering two-dimensional porous networks with $\sigma$-hole interactions of $\mathrm{Br} \cdots \mathrm{S}$ and $\mathrm{Br} \cdots \mathrm{Br}$. Chem. Mater. 2019, 31, 3041-3048. [CrossRef]

67. Mukherjee, A.; Teyssandier, J.; Hennrich, G.; De Feyter, S.; Mali, K.S. Two-dimensional crystal engineering using halogen and hydrogen bonds: Towards structural landscapes. Chem. Sci. 2017, 8, 3759-3769. [CrossRef]

68. Zheng, Q.N.; Liu, X.H.; Chen, T.; Yan, H.J.; Cook, T. Formation of halogen bond-based 2d supramolecular assemblies by electric manipulation. J. Am. Chem. Soc. 2015, 137, 6128-6131. [CrossRef]

69. Yasuda, S.; Furuya, A.; Murakoshi, K. Control of a two-dimensional molecular structure by cooperative halogen and hydrogen bonds. RSC Adv. 2014, 4, 58567-58572. [CrossRef]

70. Gutzler, R.; Fu, C.; Dadvand, A.; Hua, Y.; Macleod, J.M.; Rosei, F.; Perepichka, D.F. Halogen Bonds in 2d Supramolecular self-assembly of organic semiconductors. Nanoscale 2012, 4, 5965-5971. [CrossRef]

71. Li, J.X.; Wu, J.T.; Chen, S.W.; Miao, X.R.; Fabien, S.; Deng, W.L. Geometry symmetry of conjugated cores along $\mathrm{C}-\mathrm{Br}$ bond effect on the $2 \mathrm{~d}$ self-assembly by intermolecular $\mathrm{H} \cdots \mathrm{Br}$ and $\mathrm{Br} \cdots \mathrm{Br}$ Bonds. J. Phys. Chem. C 2018, 433, 1075-1082. [CrossRef]

72. Blanco, M.A.; Martín, P.A.; Francisco, E. Interacting quantum atoms: A correlated energy decomposition scheme based on the quantum theory of atoms in molecules. J. Chem. Theory Comput. 2005, 1, 1096-1109. [CrossRef]

73. Popelier, P.L.A. Molecular similarity and complementarity based on the theory of atoms in molecules. In Molecular Similarity in Drug Design; Dean, P.M., Ed.; Springer: Dordrecht, The Netherlands, 1995; Volume 358, pp. 215-240.

74. Wu, Y.C.; Li, J.X.; Yuan, Y.; Dong, M.Q.; Zha, B.; Miao, X.R.; Hu, Y.; Deng, W.L. Halogen bonding versus hydrogen bonding induced $2 \mathrm{~d}$ self-assembled nanostructures at the liquid-solid interface revealed by STM. Phys. Chem. Chem. Phys. 2016, 19, 3143-3150. [CrossRef] [PubMed]

75. Li, Y.; Lei, L.; Subramani, R.; Pan, Y.; Bo, L.; Yang, Y.; Chen, W.; Mamdouh, W.; Besenbacher, F.; Dong, M. Building layer-by-layer $3 \mathrm{~d}$ supramolecular nanostructures at the terephthalic acid/stearic acid interface. Chem. Commun. 2011, 47, 9155-9157. [CrossRef] [PubMed]

76. Nagula, R.G.; Bolton, O.; Burgess, E.C.; Matzger, A.J. The unprecedented size of the $\sigma$-holes on 1,3,5-triiodo-2,4,6-trinitrobenzene begets unprecedented intermolecular interactions. Cryst. Growth Des. 2016, 16, 1765-1771. 
77. Wu, J.T.; Li, J.X.; Dong, M.Q.; Miao, K.; Miao, X.R.; Wu, Y.C.; Deng, W.L. Solvent effect on host-guest two-dimensional self-assembly mediated by halogen bonding. J. Phys. Chem. C 2018, 122, 22597-22604. [CrossRef]

78. Zha, B.; Li, J.X.; Wu, J.T.; Miao, X.R.; Zhang, M. Cooperation and competition of hydrogen and halogen bonds in $2 \mathrm{~d}$ self-assembled nanostructures based on bromine substituted coumarins. New J. Chem. 2019, 43, 17182-17187. [CrossRef]

79. Zha, B.; Miao, X.R.; Li, Y.; Liu, P.; Deng, W.L. Solvent-dependent self-assembly of 4,7-dibromo-5,6bis(octyloxy)benzo[c][1,2,5] thiadiazole on graphite surface by scanning tunneling microscopy. J. Nanomater. 2013, 2013, 1-7. [CrossRef]

80. Hu, T.Z.; Wang, Y.J.; Dong, M.Q.; Wu, J.T.; Pang, P.; Miao, X.R.; Deng, W.L. Ordering self-assembly structures via intermolecular Brs interactions. Phys. Chem. Chem. Phys. 2020, 22, 1437-1443. [CrossRef]

81. Dong, M.Q.; Miao, K.; Wu, J.T.; Miao, X.R.; Li, J.X.; Pang, P.; Deng, W.L. Halogen substituent effects on concentration-controlled self-assembly of fluorenone derivatives: Halogen bond versus hydrogen bond. J. Phys. Chem. C 2019, 123, 4349-4359. [CrossRef]

82. Dong, M.Q.; Wu, J.T.; Miao, X.R.; Li, J.X.; Deng, W.L. Bromine substituent position triggered halogen versus hydrogen bond in 2d self-assembly of fluorenone derivatives. J. Phys. Chem. C 2019, 123, 26191-26200. [CrossRef]

83. Dong, M.Q.; Hu, T.Z.; Wang, Y.; Pang, P.; Wang, Y.J.; Miao, X.R.; Deng, W.L. Halogen-bonded building block for 2D self-assembly: Triggered by hydrogen-bonding motifs relative to the terminal functions of the side chains. Appl. Surf. Sci. 2020, 515, 145983-145992. [CrossRef]

84. Hu, X.Y.; Zha, B.; Wu, Y.C.; Miao, X.R.; Deng, W.L. Effects of the position and number of bromine substituents on the concentration-mediated $2 \mathrm{~d}$ self-assembly of phenanthrene derivatives. Phys. Chem. Chem. Phys. 2016, 18, 7208-7215. [CrossRef] [PubMed]

85. Pang, P.; Miao, X.R.; Ying, L.; Kong, G.; Deng, W.L. Halogen-bond-controlled self-assembly of regioisomeric phenanthridine deriatives into nanowires and nanosheets. J. Phys. Chem. C 2020, 124, 5665-5671. [CrossRef]

86. Zha, B.; Dong, M.Q.; Miao, X.R.; Peng, S.; Wu, Y.C.; Miao, K.; Hu, Y.; Deng, W.L. Cooperation and competition between halogen bonding and van der waals forces in supramolecular engineering at the aliphatic hydrocarbon/graphite interface: Position and number of bromine group effects. Nanoscale 2016, 9 , 237-250. [CrossRef] [PubMed]

87. Zha, B.; Miao, X.R.; Liu, P.; Wu, Y.C.; Deng, W.L. Concentration dependent halogen-bond density in the 2d self-assembly of a thienophenanthrene derivative at the aliphatic acid/graphite interface. Chem. Commun. 2014, 50, 9003-9006. [CrossRef]

88. Zhang, Y.; Luo, Y.; Zhang, Y.; Yu, Y.J.; Kuang, Y.M.; Zhang, L.; Meng, Q.S.; Luo, Y.; Yang, J.L.; Dong, Z.C. Visualizing coherent intermolecular dipole-dipole coupling in real space. Nature 2016, 531, 623-627. [CrossRef]

89. Zha, B.; Dong, M.Q.; Miao, X.; Miao, K.; Hu, Y.; Wu, Y.C.; Xu, L.; Deng, W.L. Controllable orientation of ester-group-induced intermolecular halogen bonding in a 2d self-assembly. J. Phys. Chem. Lett. 2016, 7, 3164-3170. [CrossRef]

90. Gutzler, R.; Ivasenko, O.; Fu, C.; Brusso, J.L.; Rosei, F.; Perepichka, D.F. Halogen bonds as stabilizing interactions in a chiral self-assembled molecular monolayer. Chem. Commun. 2011, 47, 9453-9455. [CrossRef]

91. Miao, X.R.; Li, J.X.; Zha, B.; Miao, K.; Dong, M.Q.; Wu, J.T.; Deng, W.L. Concentration-dependent multiple chirality transition in halogen-bond-driven 2d self-assembly process. Appl. Surf. Sci. 2018, 433, 1075-1082. [CrossRef]

92. Wu, J.T.; Li, J.X.; Miao, X.R.; Ying, L.; Dong, M.Q.; Deng, W.L. The brmidline horizontal ellipsis $\pi$-halogen bond assisted self-assembly of an asymmetric molecule regulated by concentration. Chem. Commun. 2020, 56, 2727-2730. [CrossRef]

Publisher's Note: MDPI stays neutral with regard to jurisdictional claims in published maps and institutional affiliations. 